\title{
Plasmodium falciparum ferredoxin-NADP+ reductase-catalyzed redox cycling of plasmodione generates both predicted key drug metabolites. Implication for antimalarial drug development
}

\author{
Bogdan Adam Cichocki, ${ }^{1, \#}$ Maxime Donzel, ${ }^{1, \#}$ Kim C. Heimsch, ${ }^{2, \#}$ Mindaugas Lesanavičius, ${ }^{3, \#}$ Liwen Feng, ${ }^{1}$ Enrique Jose \\ Montagut, ${ }^{1}$ Katja Becker, ${ }^{2}$ Alessandro Aliverti, ${ }^{4}$ Mourad Elhabiri, ${ }_{1}^{1}$ Narimantas Čènas, ${ }^{3}$ Elisabeth Davioud-Charvet, ${ }^{*}, 1$ \\ \# authors ranked by alphabetical order contributed equally as first co-authors \\ * Correspondence E-mail Address: elisabeth.davioud@unistra.fr
}

1 Université de Strasbourg-CNRS-UHA UMR7042, Laboratoire d'Innovation Moléculaire et Applications (LIMA), Team Bio(IN)organic and Medicinal Chemistry, European School of Chemistry, Polymers and Materials (ECPM), 25 Rue Becquerel, F-67087 Strasbourg, France.

2 Justus Liebig University Giessen, iFZ - Research Centre for Biosystems, Land Use and Nutrition, Department of Biochemistry and Molecular Biology, Heinrich-Buff-Ring 26-32, 35392 Giessen, Germany

3 Department of Xenobiotics Biochemistry, Institute of Biochemistry of Vilnius University, Sauletekio 7, LT-10257 Vilnius, Lithuania

4 Department of Biosciences, Università degli Studi di Milano, via Celoria 26, I-20133 Milano, Italy.

\begin{abstract}
Plasmodione (PD) is a potent antimalarial redox-active 3-benzyl-menadione acting at low nM range concentrations on different malaria parasite stages. Specific bioactivation of PD was proposed to occur via a cascade of redox reactions starting from one electron-reduction, then benzylic oxidation, leading to generation of several key metabolites including the benzylic alcohol (PD-bzol) and the 3-benzoylmenadione (PDO). In this study, we showed that benzylic oxidation of PD is closely related to the formation of a benzylic semiquinone radical, which can be produced under two conditions: UV-photoirradiation, or catalyzed by $P$. falciparum apicoplast ferredoxin-NADP ${ }^{+}$reductase (PfFNR) redox cycling in the presence of oxygen and the parent PD. Electrochemical properties of both PD metabolites were investigated in DMSO and in water. The single-electron reduction potential values of PD, PD-bzol, PDO and a series of 3-benzoylmenadiones were determined according to ascorbate oxidation kinetics. These compounds possess enhanced reactivity towards PfFNR as compared with model quinones. Optimal conditions were set up to obtain the best conversion of the starting PD to corresponding metabolites. UV-irradiation of PD in isopropanol under positive oxygen pressure led to an isolated yield of $31 \%$ PDO through the transient semiquinone species formed in a cascade of reactions. In the presence of PfFNR, PDO and PD-bzol could be observed during long lasting redox cycling of PD continuously fueled by NADPH regenerated by an enzymatic system. Finally, we

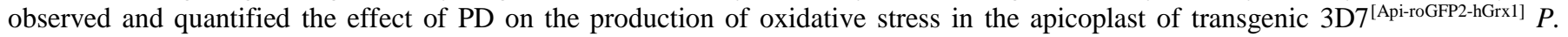
falciparum parasites by using the described genetically encoded glutathione redox sensor hGrx1-roGFP2 methodology. The observed fast ROS pulse released in the apicoplast is proposed to be mediated by PD redox cycling catalyzed by PfFNR.
\end{abstract}

KEYWORDS: apicoplast, benzylic oxidation, electrochemistry, ferredoxin-NADP ${ }^{+}$reductase, plasmodione, redox cycling 
The vulnerability of protozoan parasites to oxidative stress implies that various prooxidant compounds could be potential antiparasitic agents. ${ }^{1}$ One of the approaches in this direction is the inhibition of physiological activity of parasite antioxidant flavoenzymes responsible for maintaining the reducing milieu, or even the conversion of these antioxidant enzymes into prooxidant ones. The concept of subversive substrate (turncoat inhibitor or redox-cycler) of various disulfide oxido-reductases was established in $1988^{2}$ when menadione derivatives were observed to oxidize NADPH in the presence of oxygen and the flavoenzyme trypanothione reductase (TR). In these reactions, redox cycling of menadione derivatives, accompanied by superoxide $\left(\mathrm{O}_{2}^{-\cdot}\right)$ formation, was evidenced. Thereafter, several groups have subsequently extended this concept to nitroheteoaromatics and various 1,4-naphthoquinones (NQ) ${ }^{3-5}$ and developed these chemical series with the objective to introduce a broad structural diversity on the redox-active cores. ${ }^{6-9}$ Following these investigations on TR to develop antitrypanosomal drugs, Schirmer's group evidenced that the potent antimalarial dye, methylene blue, acts as an effective redox-cycler of various NADPH-dependent disulfide reductases including both glutathione reductases (GR) from humans ( $h \mathrm{GR}$ ) and Plasmodium falciparum (PfGR). ${ }^{10}$ However, because of the relatively low rate of quinone- and nitroreductase reactions of GR and TR, further efforts were directed to study other parasite oxidoreductases. Among those, given the data available, $P$. falciparum ferredoxin:NADP ${ }^{+}$ oxidoreductase (PfFNR) was found to possess the highest activity in redox cycling reactions with xenobiotics. ${ }^{11-13}$ This FAD-dependent enzyme catalyzes NADPH-dependent reduction of FeS-protein ferredoxin $(P f F d)$, and, like other flavoenzymes, e.g. dehydrogenases-electron transferases, transforms two-electron transfer into a single-electron one. ${ }^{14}$ Apart from high xenobiotic reductase activity of PfFNR, the importance of this enzyme is determined by its location in parasite apicoplast. ${ }^{15,16}$ The apicoplast was demonstrated to be essential for parasite survival, ${ }^{17}$ its structural or functional disruption resulting in a "delayed death" phenotype. ${ }^{18}$

This emerging strategy in redox medicinal chemistry has only been validated when the effect of redox-active compounds on flavoenzymes was accompanied by an impact on the viability of the target cells, the trypanosomes ${ }^{8}$ or malaria parasites. ${ }^{19,20}$ Later on, a proof-of-concept was established with the discovery of plasmodione (PD, Figure 1), a 3-[4-(trifluoromethyl)benzyl]menadione exerting potent antimalarial effects in the low $\mathrm{nM}$ range. ${ }^{21,22}$ Detailed enzymic kinetics ${ }^{9,21,23}$ and physico-chemical studies $^{24-27}$ have demonstrated that not only the kinetics of reduction of redox cycler, but also of re-oxidation of its reduced form is essential, to continuously fuel the redox-cycle at the expense of the reducing power of the living cell (Scheme 1). ${ }^{28}$

The chemical mechanism of action of PD has been investigated in depth by some of us over the past few years, starting from the hypothesis that PD is a prodrug, which is activated in malaria parasites through a cascade of redox reactions. First, we have identified the redox states of GR responsible for the reduction of menadione-derived subversive substrates. ${ }^{23}$ Then, we identified the antimalarial early lead agent PD, and proposed that, after reduction in the parasitized red blood cells ( $\mathrm{pRBC}$ ), PD is expected to be oxidized at the benzylic position into the corresponding benzoyl metabolite, abbreviated as PDO (for PD oxide) (Figure 1, Scheme 1, see also Figure 2 in Ref. ${ }^{21}$ ). Furthermore, we synthesized various compound pairs of structurally diverse PD/PDO derivatives and characterized the kinetics of re-oxidation of PD/PDO reduced forms, in the half reaction essential to continuously fuel the redox-cycle at the expense of NADPH (Scheme 1). ${ }^{21,26,27}$ In these studies, we demonstrated by enzymatic studies ${ }^{21}$ using both recombinant GRs of pRBC and methemoglobin $\left(\mathrm{Fe}^{3+}\right)-$ as well as by electrochemistry ${ }^{27,28}$ - that PDO is an effective subversive substrate of $h \mathrm{GR}$ and $P f \mathrm{GR}$, and more oxidant than the parent PD prodrug.

1. bioactivation *: flavoenzymes: yeast NDH and SDH, human GR, or $P$. falciparum GR and FNR

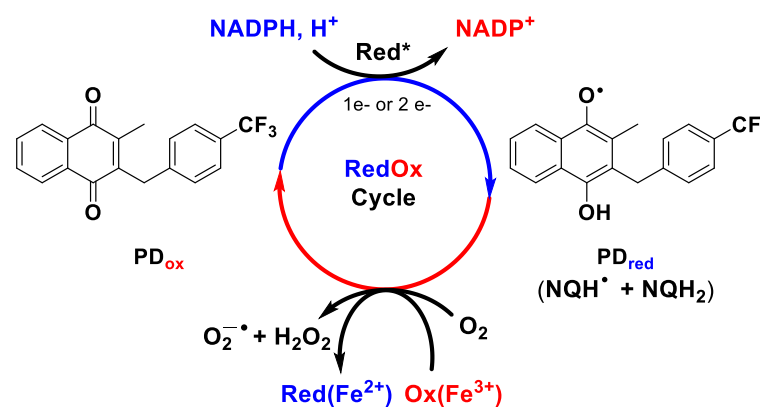

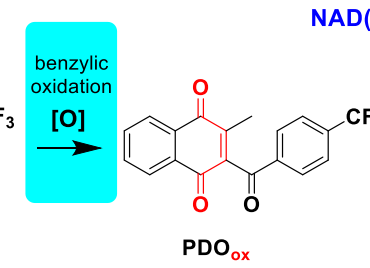

(1)

2. death of the parasite
$\operatorname{NAD}(P)^{+}$

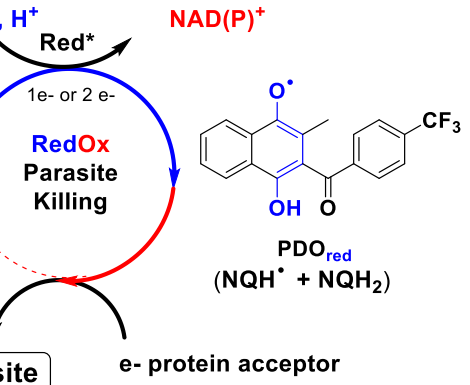

\section{this study}

Scheme 1. Proposed mechanism of action of the antimalarial early-lead plasmodione prodrug generating toxic metabolites in $P$. falciparum-parasitized red blood cells (pRBC). A first electron (e $\mathrm{e}^{-}$) transfer leading to the semiquinone $\mathrm{NQH}^{*}$ (or a two-e transfer leading to the dihydro-quinone $\mathrm{NQH}_{2}$ ) is proposed to be involved in the drug bioactivation (step 1), which can be catalyzed in enzymic assays in vitro by several relevant flavoenzymes of pRBC, including $h \mathrm{GR}$ : human glutathione reductase, PfGR: P. falciparum glutathione reductase, or PfFNR: $P$. falciparum ferredoxin-NADP ${ }^{+}$reductase (this work). For the sake of clarity, only the one-e-reduced $\mathrm{NQH}^{-}$ species was drawn in the developed structures. In step 2, we previously demonstrated that the second one-electron transfer leading to the dihydro-naphthoquinone dianion $\mathrm{NQ}^{2-}$ is highly sensitive to the nature of the benzoyl substitution $\left(p-\mathrm{CF}_{3}\right.$ in $\mathrm{PDO} v$. diverse substituted 3-benzoylmenadiones). ${ }^{29}$ This second step is thought to be responsible for parasite killing. 
<smiles>CC1C(=O)c2ccccc2C(=O)C1Cc1ccc(C(F)(F)F)cc1</smiles>

plasmodione (PD)<smiles>CC1=C(C(O)c2ccc(C(F)(F)F)cc2)C(=O)c2ccccc2C1=O</smiles>

PD-bzol

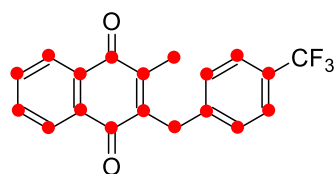

${ }^{13} \mathrm{C}_{18}$-enriched plasmodione $\left({ }^{13} \mathrm{C}_{18}\right.$-PD)

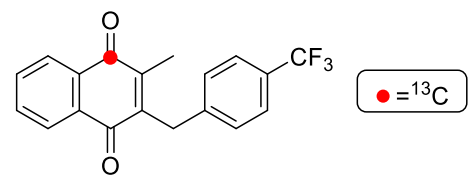

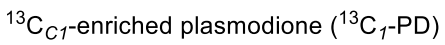<smiles>CC1=C(C(=O)c2ccc(C(F)(F)F)cc2)C(=O)c2ccccc2C1=O</smiles><smiles>[R][R]1ccc2c(c1)C(=O)C(C)=C(C(=O)c1ccc([R])cc1)C2=O</smiles>

diversely 3-benzoylmenadione derivatives

Figure 1. Structures of the chemical tools investigated in this study: the antimalarial plasmodione (PD) and both ${ }^{13} \mathrm{C}_{18 / 1 \text {-enriched representatives }}$ $\left({ }^{13} \mathrm{C}_{18}-\mathbf{P D}\right.$ and $\left.{ }^{13} \mathrm{C}_{1}-\mathbf{P D}\right)$, its two metabolites (PD-bzol and PDO), and diversely substituted 3-benzoylmenadiones.

Although we have demonstrated that PD can be chemically oxidized to PDO under harsh conditions ${ }^{21}$ we tried, for many years, to evidence the formation of PDO from PD under quasiphysiological or biomimetic conditions. To this end, three isotopically ${ }^{13} \mathrm{C}$-enriched PD and six putative PD metabolites, including its benzylic alcohol (PD-bzol for PD-benzhydrol, Figure 1) and PDO, were also synthesized and studied for their antimalarial effects. ${ }^{30}$ However, the challenge was to oxidize PD under reducing conditions, a requirement that is only possible in an enzymatic catalytic cycle, a photochemical reaction, or an electrochemical cell.

In parallel, we started to investigate the interactome of the antimalarial lead PD, using activity-based protein profiling (ABPP)-based probes and mass spectrometry analysis of the probe-protein adducts. ${ }^{31}$ In particular, we demonstrated that the UV-photoirradiation of PD-based ABPP led to their photooxidoreduction, first through NQ photoreduction and then by benzylic oxidation via oxygen insertion. Concomitantly, we used various yeast strains as model cells to study their sensitivity to PD and to decipher the mode of action (MoA) of PD by taking into consideration the power of genetic engineering in yeasts ${ }^{32,33}$ and Plasmodium parasites. ${ }^{34} \mathrm{We}$ found that PD is a potent inhibitor of yeast aerobic respiratory growth. ${ }^{32}$ Genetic and biochemical analyses showed that flavoenzymes of the mitochondrial respiratory chain, NADHdehydrogenase (NDH) and succinate dehydrogenase (SDH) play a key role in PD activity. ${ }^{32,33}$

Among the important family of flavoenzymes, there are not many representative members from $P$. falciparum, which were expressed in E.coli and described in enzyme kinetics. Because of a shortage of relevant studies on these catalyzed redox reactions using electron-acceptors, we have been using the recombinant $P f F N R$ characterized by high capability of redoxcycling in the presence of quinones as substrates ${ }^{12}$ to study the possible PD bio-activation and -transformation.

Plastidic-type members of the structural family of plant-type ferredoxin:NADP ${ }^{+}$oxidoreductase (FNR) are typically found in cyanobacteria and vegetal organisms. ${ }^{16}$ FNRs are FADdependent dehydrogenases/electron-transferases that, in conjunction with their respective partner ferredoxin $(\mathrm{Fd})$, an iron-sulfur protein, participate in the exchange of reducing equivalents between the $\mathrm{NADP}^{+} / \mathrm{NADPH}$ couple and a variety of physiological electron transporters. ${ }^{35}$ Starting from 2001, ${ }^{36}$ plastidic-type FNRs and Fds were identified and found to be expressed in the apicoplast, a Phylum-specific organelle homologous to algal plastids. ${ }^{37}$ Among the two groups of FNRs, $P$. falciparum FNR and Fd are phylogenetically related to roottype FNRs and their redox potentials are suited to support a physiological electron flow from NADPH the final electron acceptor(s) via $P f F d$ reduction. ${ }^{14}$ In particular, the redox couple was shown to fuel with reducing power the non-mevalonate pathway for the biosynthesis of isoprenoid precursors. ${ }^{38} \mathrm{~A}$ backward electron flow from reduced $P f F d$ to $\mathrm{NADP}^{+}$via $P f F N R$ is unfeasible, due to highly unfavorable redox potentials of the iron-sulfur and FAD prosthetic groups of the respective proteins. ${ }^{14,39}$ In addition, it is also possibly involved in the biogenesis of the clusters of the apicoplast iron-sulfur proteins, as well as in other housekeeping functions of the organelle. ${ }^{40}$ Similarly, because of their metabolic role(s) it is not surprising that $P f \mathrm{FNR}$ and $P f \mathrm{Fd}$ recently turned out to be both essential as demonstrated by saturation mutagenesis. ${ }^{17}$

Herein, we report a multidisciplinary approach based on electrochemistry, chemical reactivity, biochemistry, and analytical chemistry, to evaluate the properties and the substrate capacities of PD, its two metabolites PD-bzol and PDO (Figure 1) and various 3-benzoylmenadiones in PfFNR-catalyzed reactions. Furthermore, we demonstrated that the benzylic oxidation of PD could be achieved in the presence of oxygen under UV-photoirradiation, or under PfFNR catalysis at high rate of redox cycling. The structure of the formed metabolites, PD-bzol or/and PDO was confirmed by NMR spectroscopy and liquid chromatography coupled to mass spectrometry (LC-MS). In addition, the use of two isotopically ${ }^{13} \mathrm{C}$-enriched $\mathrm{PD}$ allowed us to unambiguously assign the exact molecular and fragment masses of the generated PD metabolites. Finally, the effect of $\mathrm{PD}$ on the production of ROS in the apicoplast of transgenic $3 \mathrm{D} 7^{\text {[Api-roGFP2-hGrx1] }}$ parasites was visualized by using the described genetically encoded glutathione redox sensor hGrx1roGFP2 methodology. ${ }^{41}$

\section{RESULTS AND DISCUSSION}

Redox potentials of plasmodione and its metabolites

The cytotoxicity/therapeutic activity of quinones frequently stems from their single-electron reduction by flavin-dependent 
dehydrogenases-electrontransferases, such as NADPH: cytochrome P-450 reductase or ferredoxin:NADP ${ }^{+}$ oxidoreductase, which initiate the redox cycling of their anionradicals with the subsequent formation of $\mathrm{O}_{2}^{-\cdot}$ and other activated oxygen species. ${ }^{42}$ In most cases, the single-electron reduction of quinones by above enzymes follows an ,outersphere electron transfer model, ${ }^{43}$ which is characterized by linear or parabolic dependence of $\log (k)$ from the redox potential of quinone/semiquinone couple (single-electron reduction midpoint potential, $E^{1}$, or $E^{1}{ }_{7}$ at $\mathrm{pH}$ 7.0) (Ref. ${ }^{44}$, and references therein). In turn, if quinones act mainly through the oxidative stress, their cytotoxicity increases with their $E_{7 \cdot{ }^{1}}^{42,44}$ Thus, $E^{1}$ is an important parameter for the analysis of activity of new quinone-based drugs.

The electrochemical properties of the key redox-active triad, $\mathrm{PD}$, PD-bzol and PDO, have been first examined in DMSO $\left(0.1 \mathrm{M} \mathrm{NBu}_{4} \mathrm{PF}_{6}, v=200 \mathrm{mV} / \mathrm{s}\right)$ by cyclic $(\mathrm{CV})$ and square wave (SWV) voltammetry (Figures S1-S9). ${ }^{27}$ In both systems, two consecutive one-electron quasi-reversible waves can be observed (Figure 2). The monoradical-anion $\mathrm{NQ}^{-}$is formed in the first reduction step, and subsequently reduced to its related dihydro-naphthoquinone dianion $\mathrm{NQ}^{2-}$ in a second step. For PDO, an additional ill-defined reduction wave was observed at

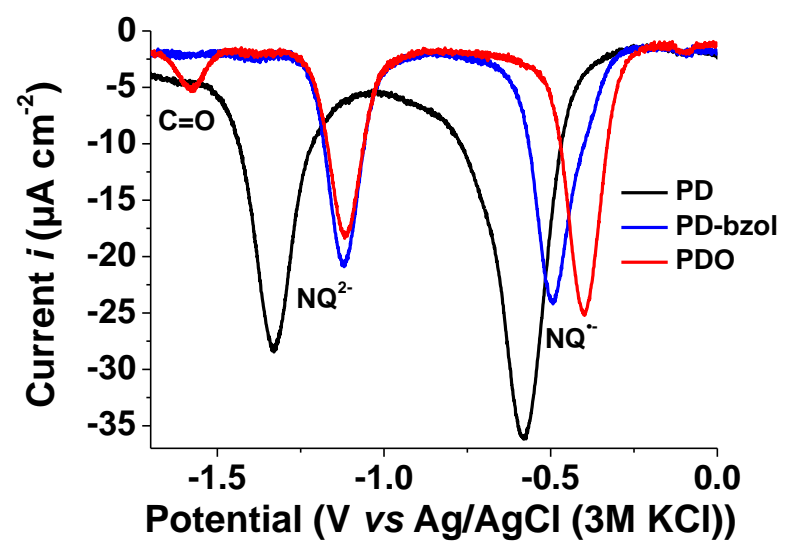

Figure 2. SWV Spectra of the PD (1.59 mM), PD-bzol (1.40 mM) and PDO (1.39 mM) triad. Solvent: DMSO; I = 0.1 M n-Bu4NPF $v=200 \mathrm{mV} \mathrm{s}^{-1}$. Reference electrode $=\mathrm{KCl}(3 \mathrm{M}) / \mathrm{Ag} / \mathrm{AgCl}$; working electrode $=$ glassy carbon disk of $0.07 \mathrm{~cm}^{2}$ area; auxiliary electrode $=\mathrm{Pt}$ wire.

much more negative values $\left(E_{1 / 2}^{3}=-1.58 \mathrm{~V}\right.$ vs. $\mathrm{KCl}(3 \mathrm{M}) / \mathrm{Ag} / \mathrm{AgCl})$ that is related to benzoyl carbonyl unit.

As far as the first electron transfer process is concerned, PD was found to be the less oxidant derivative $\left(E^{1}{ }_{1 / 2}=-0.58 \mathrm{~V} v s\right.$. $\mathrm{KCl}(3 \mathrm{M}) / \mathrm{Ag} / \mathrm{AgCl})$, while PDO is the most oxidant one $\left(E^{1}{ }_{1 / 2}\right.$ $=-0.40 \mathrm{~V} v s . \mathrm{KCl}(3 \mathrm{M}) / \mathrm{Ag} / \mathrm{AgCl}) . \mathrm{PD}-\mathrm{bzol}\left(E_{1 / 2}^{1}=-0.49 \mathrm{~V} v s\right.$. $\mathrm{KCl}(3 \mathrm{M}) / \mathrm{Ag} / \mathrm{AgCl})$ is intermediate between the PD and PDO compounds. Benzylic oxidation anodically shifts the half-wave potential $E_{1 / 2}$ of the two redox waves by about $200 \mathrm{mV}\left(E_{1 / 2}^{1}=\right.$ $-0.58 \mathrm{~V}$ for $\mathrm{PD}$ and $-0.40 \mathrm{~V} v s . \mathrm{KCl}(3 \mathrm{M}) / \mathrm{Ag} / \mathrm{AgCl}$ for $\mathrm{PDO}$, $\Delta E_{1 / 2}^{1}=210 \mathrm{mV}$ and $E_{1 / 2}^{2}=-1.33 \mathrm{~V}$ for PD and $-1.12 \mathrm{~V} v s$. $\mathrm{KCl}(3 \mathrm{M}) / \mathrm{Ag} / \mathrm{AgCl}$ for PDO, $\left.\Delta E^{2}{ }_{1 / 2}=210 \mathrm{mV}\right)$. This suggests that the benz(o)yl substitution has the same electronic effects both on the NQ unit or on its 1-electron reduced semiquinone, $\mathrm{NQ}^{-}$. PD-bzol stands in an interesting contrast with a much stronger effect on the 1-electron reduced semiquinone $\mathrm{NQ}^{-}$. than on NQ likely due to formation of a strong intramolecular hydrogen bond between the benzylic alcohol and the negatively charged semiquinone (semiNQ) subunit. Due their insufficient solubility in aqueous medium, the midpoint potentials $\left(E^{0}{ }_{7}\right)$ of quinone/hydroquinone couple of PD, PD-bzol and PDO were determined from CVs of surface-modified electrodes (Figure $\mathrm{S} 10)$ at $\mathrm{pH}$ 7. Regardless of the system considered, the CVs of PD, PD-bzol and PDO correspond to quasi-reversible waves of two-electron transfer. PD and PDO are characterized by $E^{0}{ }_{7}$ of $-0.08 \mathrm{~V}$ and $0.03 \mathrm{~V}$ vs. NHE, and by apparent rate constants of electrochemical reactions of adsorbed compounds $\left(k_{\mathrm{s}}\right)$ of 0.59 $\mathrm{s}^{-1}$ and $0.42 \mathrm{~s}^{-1}$, respectively. The $E^{0}{ }_{7}$ of PD is more negative than that of menadione (or 2-methyl-1,4-NQ), $-0.03 \mathrm{~V},{ }^{45,46}$ due to the electron-donating character of 3-benzyl substituent. Furthermore, as observed in DMSO, the presence of the 3benzoyl substituent renders the 1,4-NQ more oxidant by about $110 \mathrm{mV}$. Similarly to the first redox process in DMSO, the redox reactions of $\mathrm{PD}$-bzol take place at potentials intermediate between those of PD and PDO, but, interestingly, are characterized by two redox pairs, $E^{0}{ }_{7}=0.03 \mathrm{~V} v s$. NHE $\left(k_{\mathrm{s}}=\right.$ $1.1 \mathrm{~s}^{-1}$ ), and $E^{0}{ }_{7}=-0.03 \mathrm{~V} v$ s. NHE (Figure S10). As suggested above, hydrogen bonding between the NQ carbonyl and the secondary alcohol can be proposed to explain this peculiar behavior.

Due to instability of quinone radicals in aqueous medium, their values of $E^{1}{ }_{7}$ are obtained mainly using a pulse-radiolysis technique.$^{47}$ However, in our case this approach is hampered by insufficient solubility of PD and related 3-benzoylmenadione derivatives. Thus, we have used an alternative approach of rough estimation of $E^{1}{ }_{7}$ according to the rates of $\mathrm{O}_{2}$ consumption during quinone-mediated ascorbate oxidation (Ref. ${ }^{48}$ and references therein). In the presence of quinones with available $E^{1}{ }_{7} \leq-0.10 \mathrm{~V}$, the rate of oxygen consumption is characterized by a linear $\log (k) v s E^{1}$ relationship. The data obtained in this study (Table 1) closely matched previous results ${ }^{48}$ and were described by a well defined linear correlation:

$\log k=(2.818 \pm 0.172)+(11.663 \pm 0.728) E^{1} 7\left(r^{2}=0.966\right)$

This enabled to calculate the unavailable $E^{1} 7$ values for PD

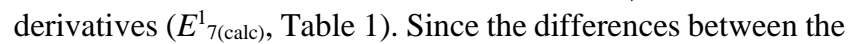
experimentally determined $E^{1}{ }_{7}$ values and $E^{1}{ }_{7 \text { (calc) }}$ do not exceed $\pm 0.03 \mathrm{~V}$ (Table 1 ), the later values are considered to be realistic.

The data obtained herein demonstrate that due to the electrondonating character of the 3-benzyl substituent, $E^{1}$ (calc.) of PD is more negative than that of menadione $14\left(2-\mathrm{CH}_{3}-1,4-\mathrm{NQ}\right)$ (Table 1). The presence of electron accepting 3-benzoyl substituent increases $E^{1}$ of PDO, which becomes close to that of 1,4-NQ 12 (Table 1). The $E^{1}{ }_{7}$ value of PD-bzol is intermediate between those of PD and PDO (Table 1). Among

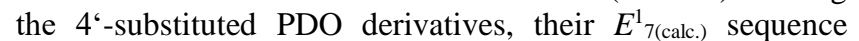
closely matches the $\sigma_{\mathrm{p}}$ values of substituents ${ }^{49}: \mathbf{5}\left(-\mathrm{NO}_{2}, \sigma_{\mathrm{p}}=\right.$ $0.78) \geq \operatorname{PDO}\left(-\mathrm{CF}_{3}, \sigma_{\mathrm{p}}=0.54\right)>\mathbf{6}\left(-\mathrm{C} \equiv \mathrm{CH}, \sigma_{\mathrm{p}}=0.23\right) \geq \mathbf{7}(-\mathrm{Br}$, $\left.\sigma_{\mathrm{p}}=0.23\right)($ Table 1$)$ in agreement with reported values. ${ }^{27}$ 
Table 1. Rate constants $(k)$ of ascorbate oxidation by quinones and 3-benz(o)ylmenadione derivatives, their experimentally determined $E^{1}{ }_{7}$ values, ${ }^{47}$ and $E^{1}{ }_{7}$ values calculated according to Equation (1) $\left(E^{1}{ }_{7}\right)$.<smiles>CC1=C(Cc2ccc(C(F)(F)F)cc2)C(=O)c2ccccc2C1=O</smiles>

PD<smiles>COc1ccc(OC)c(C(=O)C2=C(C)C(=O)c3ccccc3C2=O)c1</smiles>

2

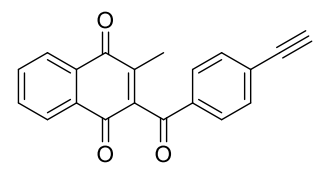

6<smiles>CC1=C(C(O)c2ccc(C(F)(F)F)cc2)C(=O)c2ccccc2C1=O</smiles>

PD-bzol<smiles>COc1cc(OC)cc(C(=O)C2=C(C)C(=O)c3ccccc3C2=O)c1</smiles><smiles>CC1=C(C(=O)c2ccc(Br)cc2)C(=O)c2ccccc2C1=O</smiles>

7<smiles>CC1=C(C(=O)c2ccc(C(F)(F)F)cc2)C(=O)c2ccccc2C1=O</smiles><smiles></smiles><smiles>CC1=C(C(=O)c2ccc([N+](=O)[O-])cc2)C(=O)c2ccccc2C1=O</smiles>

\begin{tabular}{|c|c|c|c|}
\hline Quinone & $k\left(\mathrm{M}^{-1} \mathrm{~s}^{-1}\right)$ & $E^{1}{ }_{7}(\mathrm{~V})$ & $E_{7 \text { (calc.) }}^{1}(\mathrm{~V})$ \\
\hline PD & $0.30 \pm 0.02$ & - & $-0.286 \pm 0.024$ \\
\hline PD-bzol & $1.17 \pm 0.36$ & & $-0.236 \pm 0.024$ \\
\hline PDO & $4.62 \pm 0.99$ & - & $-0.185 \pm 0.019$ \\
\hline 1 & $1.12 \pm 0.13$ & - & $-0.238 \pm 0.022$ \\
\hline 2 & $0.43 \pm 0.07$ & - & $-0.273 \pm 0.023$ \\
\hline 3 & $2.89 \pm 0.46$ & - & $-0.202 \pm 0.020$ \\
\hline 4 & $4.75 \pm 0.53$ & - & $-0.183 \pm 0.017$ \\
\hline 5 & $5.60 \pm 0.53$ & - & $-0.169 \pm 0.018$ \\
\hline 6 & $1.10 \pm 0.2$ & - & $-0.238 \pm 0.022$ \\
\hline 7 & $0.81 \pm 0.14$ & - & $-0.249 \pm 0.022$ \\
\hline 8 & $13.9 \pm 1.9$ & - & $-0.144 \pm 0.018$ \\
\hline 5-OH-1,4-Napthoquinone 9 & $53.5 \pm 6.7$ & -0.09 & $-0.093 \pm 0.017$ \\
\hline 5,8-(OH $)_{2}-1,4-$ Naphthoquinone $\mathbf{1 0}$ & $48.9 \pm 5.2$ & -0.11 & $-0.097 \pm 0.016$ \\
\hline 9,10-Phenanthrene quinone $\mathbf{1 1}$ & $15.2 \pm 0.9$ & -0.12 & $-0.14 \pm 0.017$ \\
\hline 1,4-Naphthoquinone $\mathbf{1 2}$ & $15.9 \pm 1.4$ & -0.15 & $-0.139 \pm 0.017$ \\
\hline$\left(\mathrm{CH}_{3}\right)_{3}-1,4$-Benzoquinone $\mathbf{1 3}$ & $16.5 \pm 1.8$ & -0.17 & $-0.137 \pm 0.018$ \\
\hline 2- $\mathrm{CH}_{3}$-1,4-Naphthoquinone 14 & $2.38 \pm 0.5$ & -0.20 & $-0.209 \pm 0.021$ \\
\hline$\left(\mathrm{CH}_{3}\right)_{4}-1,4$-Benzoquinone $\mathbf{1 5}$ & $0.3 \pm 0.05$ & -0.26 & $-0.286 \pm 0.024$ \\
\hline $1,8-(\mathrm{OH})_{2}-9,10$-Anthraquinone $\mathbf{1 6}$ & $0.136 \pm 0.02$ & -0.30 & $-0.316 \pm 0.025$ \\
\hline $1,4-(\mathrm{OH})_{2}-9,10$-Anthraquinone $\mathbf{1 7}$ & $0.091 \pm 0.009$ & -0.33 & $-0.331 \pm 0.026$ \\
\hline 2-OH-1,4-Naphthoquinone $\mathbf{1 8}$ & $0.018 \pm 0.003$ & -0.41 & $-0.391 \pm 0.029$ \\
\hline
\end{tabular}

In turn, the formation of H-bonds of quinone carbonyl groups with 5(8)-OH substituents increases $E^{1}$ of 1,4-NQs (Table 1). ${ }^{47}$ This phenomenon is evidenced by an increase of $E^{1}$ 7(calc) of 5OH-substituted 3-benzoylmenadione 8 with respect to the unsubstituted analogue 7 (Table 1).

\section{3-Benzoyl menadione reductase activity of PfFNR}

Based on our data, PfFNR may play a central role in the reductive activation of prooxidant xenobiotics relevant for malaria chemotherapy. ${ }^{13}$ The steady-state kinetic parameters of PfFNR-catalyzed reduction of PD derivatives, i.e. the apparent catalytic constants $\left(k_{\mathrm{cat}(\mathrm{app})}\right)$ and the bimolecular rate constants (or catalytic efficiency constants, $k_{\mathrm{cat}} / K_{\mathrm{m}}$ ) for the oxidants at fixed NADPH concentration are given in Table 2. The quinonedependent enzymatic NADPH oxidation is accompanied by the superoxide dismutase (SOD)-sensitive reduction of added cytochrome $c$ (cyt $c$ ) (Table 2), which points to the singleelectron character of quinone reduction, accompanied by redox cycling and $\mathrm{O}_{2}^{-\cdot}$ formation. Both Michaelis-Menten and Lineweaver-Burk plots for the PfFNR-catalyzed reduction of the 3-benzoyl menadione PDO are shown in Figure S11. In both case, no deviation was observed from both types of plots. 


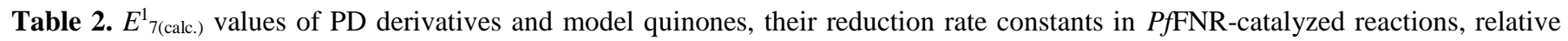
cytochrome $c$ reduction rates $v_{\mathrm{i}}(\mathrm{cyt} c) / v_{\mathrm{i}}(\mathrm{NADPH})$ and their sensitivity to $100 \mathrm{U} / \mathrm{ml}$ superoxide dismutase (SOD), and calculated $\log D$ values.

\begin{tabular}{|c|c|c|c|c|c|c|}
\hline \multirow[b]{2}{*}{ Compound } & \multirow{2}{*}{$\begin{array}{c}E^{1} 7 \text { (calc.) } \\
\text { (V) }\end{array}$} & \multicolumn{2}{|c|}{ Reactivity with PfFNR } & \multirow{2}{*}{$\begin{array}{c}v_{i}(\text { cyt } c) / \\
v_{i}(\mathrm{NADPH}) \\
(\%)\end{array}$} & \multirow{2}{*}{$\begin{array}{c}\text { Inhibition by } \\
\text { SOD }(\%)\end{array}$} & \multirow[b]{2}{*}{$\log D$} \\
\hline & & $\begin{array}{l}k_{\text {cat }} \\
\left(\mathrm{s}^{-1}\right)\end{array}$ & $\begin{array}{c}k_{\mathrm{cat}} / K_{\mathrm{m}} \\
\left(\mathrm{M}^{-1} \mathrm{~s}^{-1}\right)\end{array}$ & & & \\
\hline PD & $-0.286 \pm 0.024$ & 2.6 & $1.44 \times 10^{5}$ & 146 & 94 & 4.74 \\
\hline PD-bzol & $-0.236 \pm 0.024$ & 5.8 & $1.25 \times 10^{6}$ & 195 & 48 & 3.67 \\
\hline PDO & $-0.185 \pm 0.019$ & 4.3 & $9.96 \times 10^{5}$ & 195 & 46 & 4.11 \\
\hline 1 & $-0.238 \pm 0.022$ & 3.1 & $5.97 \times 10^{5}$ & 169 & 52 & 4.25 \\
\hline 2 & $-0.273 \pm 0.023$ & 12.3 & $4.95 \times 10^{5}$ & 180 & 19 & 2.92 \\
\hline 3 & $-0.202 \pm 0.020$ & 12 & $9.4 \times 10^{5}$ & 193 & 30 & 2.92 \\
\hline 4 & $-0.183 \pm 0.017$ & 10.2 & $8.21 \times 10^{5}$ & 164 & 75 & 3.17 \\
\hline 5 & $-0.169 \pm 0.018$ & 6.4 & $2.34 \times 10^{6}$ & 182 & 31 & 3.17 \\
\hline 6 & $-0.238 \pm 0.022$ & 13.3 & $8.3 \times 10^{5}$ & 186 & 28 & 3.38 \\
\hline 7 & $-0.249 \pm 0.022$ & 5.6 & $2.2 \times 10^{6}$ & 195 & 36 & 4.0 \\
\hline 8 & $-0.144 \pm 0.018$ & 12.7 & $1.8 \times 10^{6}$ & 192 & 19 & 4.28 \\
\hline 5-OH-1,4-naphthoquinone $9^{\mathrm{a}}$ & $-0.093 \pm 0.017$ & 35.7 & $1.1 \times 10^{6}$ & & & 1.82 \\
\hline $5,8-(\mathrm{OH})_{2}-1,4-$-naphthoquinone $\mathbf{1 0}^{\mathrm{a}}$ & $-0.097 \pm 0.016$ & 25.0 & $4.1 \times 10^{5}$ & & & 2.17 \\
\hline 1,4-Naphthoquinone $\mathbf{1 2}^{\mathrm{a}}$ & $-0.139 \pm 0.017$ & 16.9 & $3.1 \times 10^{5}$ & & & 1.5 \\
\hline 2- $\mathrm{CH}_{3}-1,4-$-naphthoquinone $\mathbf{1 4}^{\mathrm{a}}$ & $-0.209 \pm 0.021$ & 26.5 & $2.6 \times 10^{5}$ & 190 & 50 & 1.89 \\
\hline 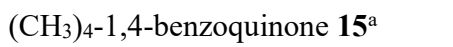 & $-0.286 \pm 0.024$ & 33.1 & $7.2 \times 10^{4}$ & & & 2.61 \\
\hline 2-OH-1,4-naphthoquinone $\mathbf{1 6}^{\mathrm{a}}$ & $-0.391 \pm 0.029$ & 2.6 & $9.8 \times 10^{3}$ & & & -0.7 \\
\hline
\end{tabular}

One may note that the coupled cyt $c$ reduction by high-potential PDO derivatives is less sensitive to SOD in comparison with low-potential ones like PD (Table 2). This is because high potential semiquinones, being engaged in a redox equilibrium with the $\mathrm{O}_{2} / \mathrm{O}_{2}{ }^{-\bullet}$ couple, will yield a lower amount of $\mathrm{O}_{2}{ }^{-}$as compared with low-potential semiquinones. Thus, the reduction of cyt $c$ mediated by quinones with higher $E^{1}{ }_{7 \text { (calc.) }}$ should be less sensitive to the action of SOD..$^{50}$

The reactivity of PfFNR towards model quinones $\left(\log k_{\text {cat }} / K_{\mathrm{m}}\right)$ exhibits linear dependence with their $E^{1}{ }_{7 \cdot}{ }^{13}$ Interestingly, the reactivity of most 3-benz(o)ylmenadione derivatives is much higher than that of model benzo- and NQs with similar $E_{7 \text { (calc) }}^{1}$ values (Figure 3 ).

The nature of this phenomenon deserves further studies. One of the possible reasons may be the high lipophilicity of these 3benz(o)ylmenadione derivatives $(\log D)$, in most cases significantly exceeding that of model quinones (Table 1).

Indeed, the most solvent-accessible portion of the flavin ring system in PfFNR, i.e., its dimethyl-benzene moiety as well its protein microenvironment, which includes residues Leu102, Tyr159, Val315 and Tyr315, possess a clear hydrophobic character. $^{51}$

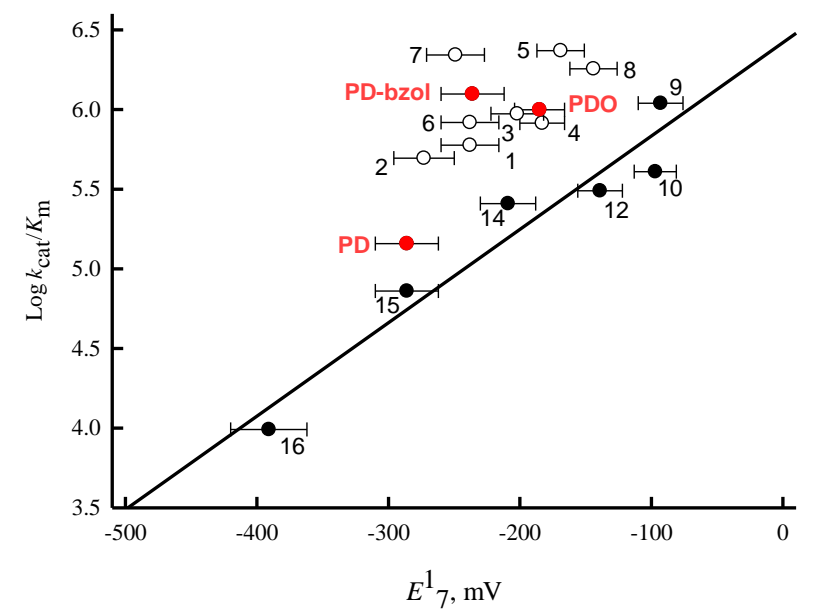

Figure 3. Relationship between the reactivity of PfFNR towards PD, PD-bzol, PDO, PDO derivatives 1-8, and model quinones 916, and their $E^{1} 7$ (calc) values. The numbers of compounds are taken from Table 2. The straight line represents the best linear fit of data related only to model quinones $\mathbf{9 , 1 0 , 1 2 , 1 4 - 1 6}$. 
Also, while FNRs are highly specific for the NADP ${ }^{+} / \mathrm{NADPH}$ couple, they are able to reduce a large variety of nonphysiological electron acceptors, of biological, organic and inorganic nature. At variance with other plastidic-type FNRs, which display high-turnover numbers, PfFNR has a particularly low $k_{\text {cat }}$ in the physiological reaction. ${ }^{14}$ This is mainly due to an impaired electron transfer from the reduced enzyme to the protein partner. Because neither the stability of the PfFNR-PfFd complex nor the $K_{\mathrm{m}}$ of the enzyme for $P f \mathrm{Fd}$ are particularly hampered in comparison to other FNRs, a possible explanation could be the poor thermodynamic stabilization of FAD semiquinone observed in PfFNR, ${ }^{14}$ as compared to other plastidic FNRs. Interestingly, PfFd was previously shown to stimulate quinone reductase activity of $P f \mathrm{FNR}$ providing an alternative pathway of quinone reduction via reduced $P f F d .{ }^{13}$

\section{Photo-catalyzed benzylic oxidation of PD to PDO}

To gain a better understanding of the mechanism of benzylic oxidation of PD to PDO in the presence of oxygen we mimicked, with a simple system, the redox cycle responsible of this reaction. UV-photoreduction of quinones in 2-propanol (iPrOH, or isopropanol) is known to generate, among other species, semiquinone radicals. ${ }^{52}$

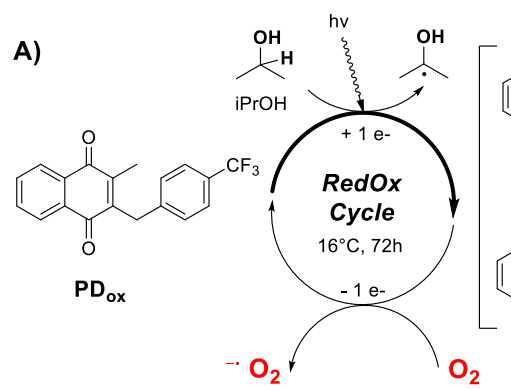

B)

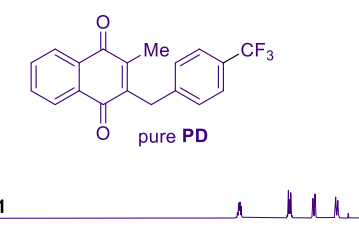

PD in iPrOH irradiated $72 \mathrm{~h}$ under UV ligh

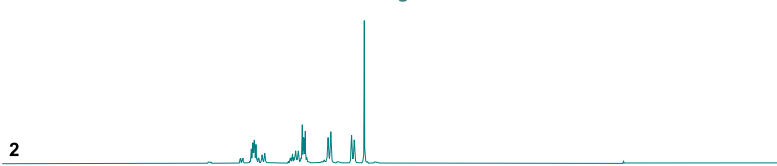

PD in iPrOH irradiated $72 \mathrm{~h}$ under $\psi \mathrm{V}$ light and $\mathrm{O}_{2}$ atmospher

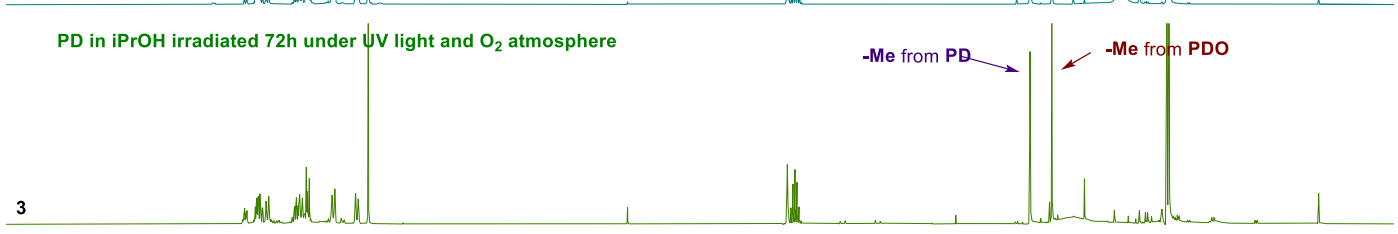

(20.0

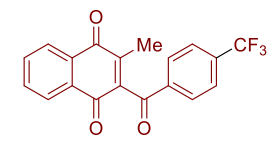

pure PDO

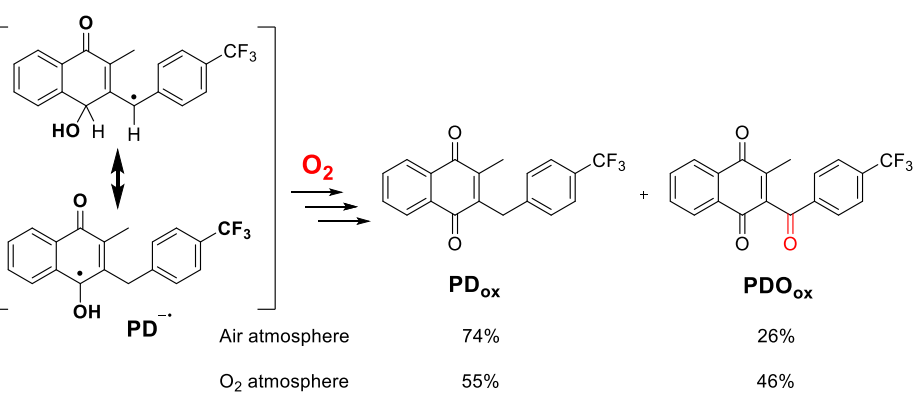

$\mathrm{O}_{2}$ atmosphere (isolated yield : $\mathbf{3 1 \%}$ )
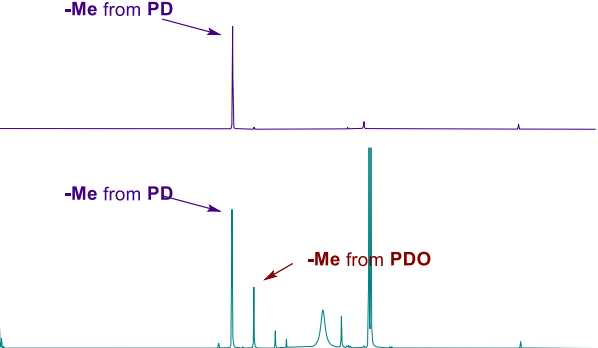

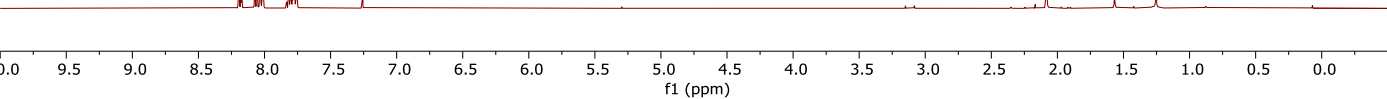

C)

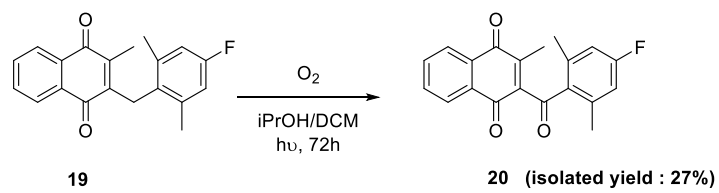

Figure 4. Photo-catalyzed oxidation of PD to PDO and of the bulky 3-benzylmenadione 19 to the corresponding 3-benzoylmenadione 20. A) The reaction with $\mathrm{PD}$ was performed in $\mathrm{PPOH}$ under two distinct conditions: in open air or in oxygen atmosphere. B) Overlay of the ${ }^{1} \mathrm{H} \mathrm{NMR}$ spectra in the 2.8-3.4 ppm area of pure PD (spectrum 1), reaction mixtures of PD after $72 \mathrm{~h} \mathrm{UV}$-photoirradiation at $350 \mathrm{~nm}$ in iPrOH: under air atmosphere (spectrum 2), or in $\mathrm{O}_{2}$ atmosphere (spectrum 3); and pure 3-benzoylmenadione PDO (spectrum 4). C) Photooxidation of 3benzylmenadione 19 to the 3-benzoylmenadione $\mathbf{2 0}$ in $\mathrm{iPrOH} / \mathrm{DCM}$ mixture. $\mathrm{PD}^{-*}$ stands for one electron-reduced PD semiquinone species. 
Upon UV irradiation, PD is photo-excited and the generated excited triplet state of the quinone is quenched by $\mathrm{iPrOH}(\mathrm{H}$ atom donor) to form the anionic semiNQ radical. This gives the advantage to provide an artificial way to generate the targeted radical species, which is essential for the formation of the benzylic oxidation product, i.e. PDO from PD (Figure 4A). Under air atmosphere and after $72 \mathrm{~h}$ of irradiation at $350 \mathrm{~nm}$ we observed a significant conversion of PD to PDO (ratio 74/26) without any major side product (Figure $4 \mathrm{~B},{ }^{1} \mathrm{H}$ NMR spectra 1 to 4). The same reaction performed under a positive pressure of oxygen led to an even better conversion of the starting PD to the oxidized PDO (ratio 55/45) and an isolated yield of $31 \%$. These observations confirm that PD can be oxidized through the transient anionic semiNQ species in a cascade of reactions leading to the observed PDO. A putative mechanism is proposed in Scheme 2.

With this new methodology well established, we then applied it to obtain the bulky 3-benzoylmenadione 20, which could not be easily obtained by other methods. This allowed us to determine if steric hindrance could be a limiting factor for benzylic photooxidation. A slight modification was however necessary, especially to solubilize the starting material by adding dichloromethane (DCM) as a co-solvent. We observed that starting 3-benzylmenadione 19 was totally consumed after $72 \mathrm{~h}$ irradiation, but with a significant amount of degradation products. The target product $\mathbf{2 0}$ was isolated with a modest yield of $27 \%$ (Figure 4C).

\section{PfFNR catalyzes the benzylic oxidation of plasmodione}

During long lasting redox cycling turnover of PfFNR in the presence of PD, NADPH and oxygen, we raised the question on the possibility of benzylic oxidation of PD to PD-bzol and/or PDO. To validate whether PfFNR indeed generates PDO during PD redox cycling, we analyzed by LC-ESI-MS a reaction mixture of PD and PfFNR subjected to redox cycling by repetitive addition of NADPH. As shown in Figure 5 we could clearly detect the formation of increasing amount of reduced PDO species, $\mathrm{PDO}_{\text {red, }}$ generated from $\mathrm{PD}$, from 30 min to $2 \mathrm{~h}$ incubation with PfFNR (Figures 5A and 5B). However, this transformation was observed only when PfFNR was present (Figure S12). Noteworthy is the fact that these experiments are much longer than the steady-state kinetic assays for reduction of PDO derivatives by PfFNR for 5-7 min. Importantly, no PDO formation was evidenced when as the catalyst $h \mathrm{GR}$ was present in the reaction (Figure S13).

Furthermore, we found that the presence of cyt $c$ in the reaction significantly increased the rate of $\mathrm{PDO}_{\text {red }}$ formation. With its prosthetic heme group $\left(\mathrm{Fe}^{3+}\right.$ center), it may additionally accept electrons from the reduced PD during redox cycling. By reoxidizing the reduced PD species, cyt $c$ accelerates PfFNRcatalyzed redox cycling, which is responsible for $\mathrm{PD}$ reduction to semiquinone. To further test whether PfFNR is able to generate PDO, we repeated the experiments using an NADPHregenerating system based on glucose-6-phosphate dehydrogenase (G6PD), glucose-6-phosphate and $\mathrm{NADP}^{+}$, to redox-cycle PD continuously. This ensures the generation of a constant flux of NADPH, which more closely resembles physiological conditions compared to the repetitive addition of high concentrations of NADPH.
Additionally, to support metabolite identification during LCMS PD was mixed in reaction with the isotopically-heavier PD $(1 / 1)$, namely the ${ }^{13} \mathrm{C}$-enriched either at all carbon atoms except at the $\mathrm{CF}_{3}$ group $\left({ }^{13} \mathrm{C}_{18}-\mathrm{PD}\right)$, which the 10 step-long total synthesis was reported earlier ${ }^{30}$ or at carbon-1 position $\left({ }^{13} \mathrm{C}_{l^{-}}\right.$ $\mathrm{PD})$. During MS analysis these heavier ${ }^{13} \mathrm{C}_{18 / 1}$-PD versions generate, compared to the original compound, a mass shift corresponding to the degree of ${ }^{13} \mathrm{C}$-enrichment $(\Delta m / z=+18$ or +1 ), which increases the confidence of identification (Scheme $\mathrm{S} 2)$.

When PD $/{ }^{13} \mathrm{C}$-enriched PD (1/1) mixture was introduced in the redox cycling reaction with PfFNR fueled by the G6PD system, we evidenced both anticipated reduced PD metabolite species in reaction: the reduced PD-bzol $(\mathrm{RT}=40.5 \mathrm{~min}), \mathrm{PD}_{-\mathrm{bzol}}$ red, which is believed to be the second metabolite during the formation of PDO (Scheme 2), was detected in addition to $\mathrm{PDO}_{\text {red }}$ (Figure 6). This finding directly confirms the formation of the active PD-bzol and PDO metabolites from PD during enzymatic cycling. Importantly, the same metabolites were detected for both ${ }^{13} \mathrm{C}$-enriched drugs as well as the nonenriched drug (Figure 6 and Scheme S2). Analysis of the chromatography peaks indicate that 5 to $10 \%$ of PD is already converted after 2 hours.

Interestingly, PD-bzol ${ }_{\mathrm{ox}},\left([\mathrm{M}+\mathrm{H}]^{+}=347.09\right)$ but not $\mathrm{PDO}_{\mathrm{red}}$ $\left([\mathrm{M}+\mathrm{H}]^{+}=347.09\right)$, loses $18 \mathrm{Da}$ fragment during MS analysis (Figures 6 and S14) indicating that the fragment [M-18] can unambiguously be used to assign the presence of PD-bzol. Of note, the lack of fragment [M-18] in the MS spectrum of the species at RT $=41.9$ min indicates that the identified compound with $m / z=346.08$ is the diprotonated reduced $\mathrm{PDO}_{\text {red }}$ (exact mass $=346.08$ ), and not the oxidized PD-bzol ${ }_{\text {ox }}$ (exact mass = 346.08), with which it shares an identical exact mass and RT (Figure $\mathrm{S} 14$ ). In the same vein, the use of $\mathrm{PD} /{ }^{13} \mathrm{C}_{18 / 1}$-enriched $\mathrm{PD}$ mixture (1/1) in cycling reaction makes it possible to differentiate at RT $=41.9 \mathrm{~min}$ between the $\mathrm{m} / \mathrm{z}$, pair PD-bzol ${ }_{\mathrm{ox}}$, $\left([\mathrm{M}+\mathrm{H}]^{+}=347.09\right)$ and $\mathrm{PDO}_{\text {red }}\left([\mathrm{M}+\mathrm{H}]^{+}=347.09\right)$, although traces of $-18 \mathrm{Da}$ fragments can be detected $\left([\mathrm{M}-18+\mathrm{H}]^{+}=\right.$ 329.09 for PD-bzol $-\mathrm{H}_{2} \mathrm{O}$ fragment and 330.10 for ${ }^{13} \mathrm{C}_{l^{-}}$ enriched PD-bzol $-\mathrm{H}_{2} \mathrm{O}$ fragment) indicating that also the PDbzol might be formed in minor amounts (Figure 6A and Scheme $\mathrm{S} 2)$. While PD $/{ }^{13} \mathrm{C}_{18}$-enriched PD (1/1) mixture generates three $\mathrm{m} / \mathrm{z}$, peaks at $\mathrm{RT}=40.5 \mathrm{~min}, 331.09,349.14$, and 367.16 (Figure 6B and Scheme S2), LC-MS analysis allowed us to respectively assign the mass peaks to $m / z$ PD-bzol ${ }_{\text {red }}-\mathrm{H}_{2} \mathrm{O}$ fragment ([M$\left.18+\mathrm{H}]^{+}=331.09\right), m / z$ PD-bzol red $\left([\mathrm{M}+\mathrm{H}]^{+}=349.10\right)$ merged with $m / z^{13} \mathrm{C}_{18}$-enriched PD-bzol ${ }_{\text {red }}-\mathrm{H}_{2} \mathrm{O}$ fragment ([M-18+H $]^{+}$ $=349.15)$, and $\mathrm{m} / z{ }^{13} \mathrm{C}_{18}$-enriched PD-bzol ${ }_{\text {red }}\left([\mathrm{M}+\mathrm{H}]^{+}=\right.$ 367.16). Because the loss of $18 \mathrm{Da}$ could be attributed to both the loss of $\mathrm{H}_{2} \mathrm{O}$ during $\mathrm{MS}$ analysis and the ${ }^{13} \mathrm{C}_{18}$ enrichment at 18 carbons (see the previously observed merged $\mathrm{m} / \mathrm{z}$ peak at 349.14), we could conclude on the right assignment in the experiment using PD $/{ }^{13} \mathrm{C}_{l}$-enriched PD (1/1) mixture (Figure 6C and Scheme S2). In the MS spectra of the chromatography peak at RT $=40.5 \mathrm{~min}$ were observed the peaks at $\mathrm{m} / \mathrm{z} 331.09$, $332.09,349.11$, and 350.11 , assigned to the four generated species: PD-bzol ${ }_{\text {red }}-\mathrm{H}_{2} \mathrm{O}$ fragment $\left([\mathrm{M}-18+\mathrm{H}]^{+} \mathrm{m} / z=331.09\right)$, ${ }^{13} \mathrm{C}_{l}$-enriched PD-bzol ${ }_{\text {red }}-\mathrm{H}_{2} \mathrm{O}$ fragment $\left([\mathrm{M}-18+\mathrm{H}]^{+} \mathrm{m} / \mathrm{z}=\right.$ 332.10), $\mathrm{PD}-$ bzol $_{\text {red }}\left([\mathrm{M}+\mathrm{H}]^{+} \mathrm{m} / z=349.10\right)$, and ${ }^{13} \mathrm{C}_{l}$-enriched

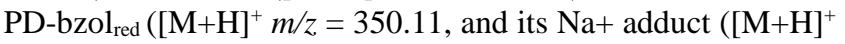
$m / z=371.10)$. 
It is important to state here that the identified reduced PD metabolite species are not an artefact of the MS analysis. Not only they have different RT compared to the controls, i.e. the pure oxidized PD-bzol ${ }_{\mathrm{ox}}$ and $\mathrm{PDO}_{\mathrm{ox}}$, but also the controls were not reduced in the source of the MS spectrometer. In other words the cause of PD-bzol ${ }_{\mathrm{ox}}$ and $\mathrm{PDO}_{\mathrm{ox}}$ reduction is in the PfFNR-catalyzed reaction. This important observation demonstrates that the major PD-bzol and PDO metabolites are predominantly present as reduced species in the presence of potent reductants like the NADPH-reduced PfFNR. This situation is similar with that of methylene blue, which mainly exists as leucomethylene blue in vivo.

\section{Proposed Mechanism of benzylic oxidation through redox cycling in the presence of oxygen}

Scheme 2 displays the proposed mechanism of aerobic benzylic oxidation of PD, under redox cycling, to its corresponding benzhydrol (PD-bzol) and 3-benzoylmenadione (PDO) metabolites. Although less effective than with PDO $\left(E_{1 / 2}^{1}=-\right.$ $0.40 \mathrm{~V}$ vs. $\mathrm{KCl}(3 \mathrm{M}) / \mathrm{Ag} / \mathrm{AgCl}$ in $\mathrm{DMSO}$ or $E^{0}{ }_{7}=0.03 \mathrm{~V}$ vs. NHE in water), PD can undergo an one-electron transfer to lead to semiNQ species $\mathrm{PD}^{-\cdot}\left(E^{1}{ }_{1 / 2}=-0.58 \mathrm{~V} v\right.$ s. $\mathrm{KCl}(3 \mathrm{M}) / \mathrm{Ag} / \mathrm{AgCl}$ in DMSO or $E^{0}{ }_{7}=-0.08 \mathrm{~V} v s$. NHE in water) under NADPHdependent reducing flavoenzyme catalysis (e.g., both GR, $P f$ FNR in this work).
Flavoenzymes, e.g. PfFNR in this work, act as biocatalysts that initiate the redox cycling cascade leading to formation of both PD-bzol and PDO. The one electron-reduced $\mathrm{PD}^{-\bullet}$ semiquinone can react rapidly with molecular $\mathrm{O}_{2}$ to regenerate $\mathrm{PD}_{\mathrm{ox}}$ and superoxide radicals $\mathrm{O}_{2}^{-}$. In aqueous solutions, the anionic $\mathrm{PD}^{--}$ semiquinone undergoes protonation releasing a protonated $\mathrm{PDH}^{*}$ (Scheme 2, species a). $\mathrm{PDH}^{*}$ is then proposed to be submitted to tautomerization leading to the corresponding stable benzylic radical (Scheme 2, species b). The resulting carbon-centered radical is anticipated to be readily trapped by dioxygen to give the peroxyl radical (Scheme 2, species c). Tautomerization (Scheme 2, species d) and subsequent dehydration leads to the PDO' semiquinone species (Scheme 2, species e) that can rapidly react with $\mathrm{O}_{2}$ to generate the PDO metabolite and $\mathrm{O}_{2}^{-\bullet}$. Interestingly, the one-electron reduced PDO semiquinone can also tautomerize into the stable $C$ centered benzylic alcohol radical (Scheme 2, species f). The radical intermediate $\mathrm{f}$ can then, either be reduced in PfFNR redox cycling, or disproportionate into PD-bzol ${ }_{\text {red }}+$ PD-bzol $_{\mathrm{ox}}$, respectively. The proposed mechanism pathway (Scheme 2), initiated by one electron-reduction of the NQ core thus relies on key benzylic radical (species b) and the $C$-centered radical (species f), for the generation of PDO and PD-bzol metabolites, via oxygen scavenging/tautomerization/disproportionation.

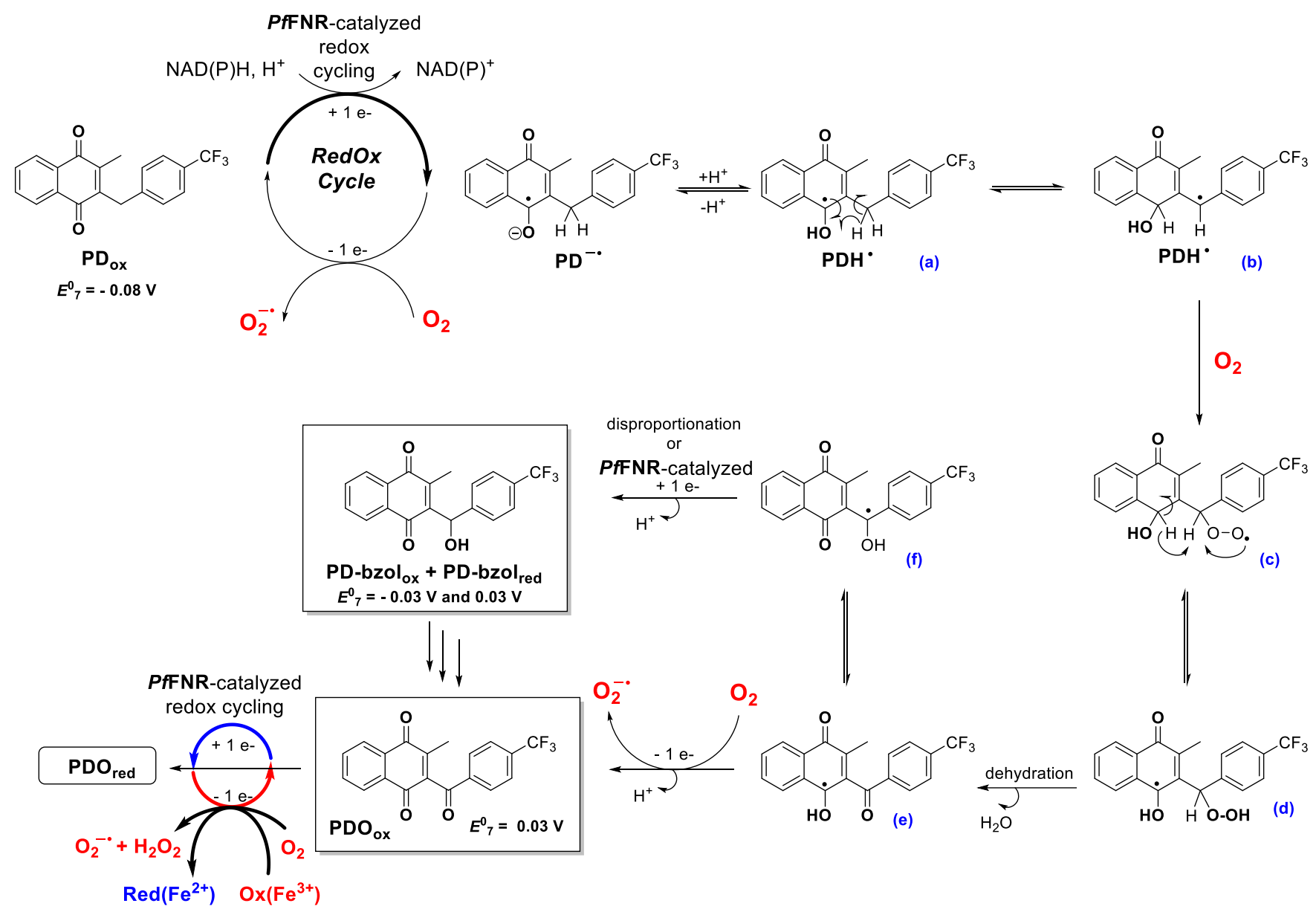

Scheme 2. Proposed mechanism of the aerobic PfFNR-catalyzed benzylic oxidation of plasmodione, to the corresponding benzhydrol (PD-bzol) and the 3-benzoylmenadione (PDO), via the formation of the semiquinone radical $\mathrm{PD}^{-\bullet}$, upon one electron-reduction, and its protonated radical species $\mathrm{PDH}^{\bullet}$. $\mathrm{PD}^{-}$stands for one electron-reduced $\mathrm{PD}$ semiquinone species. 
A)

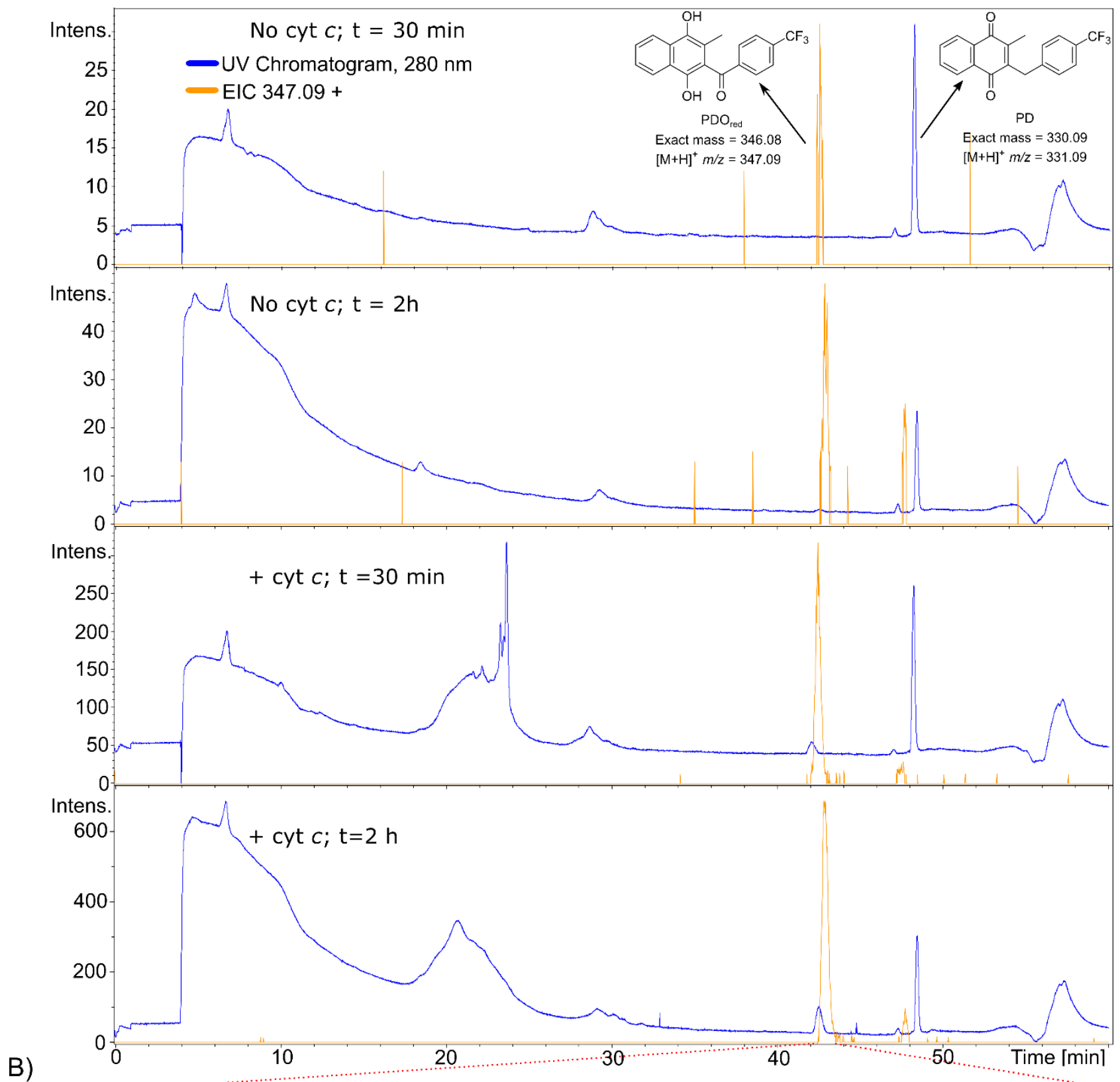

B)

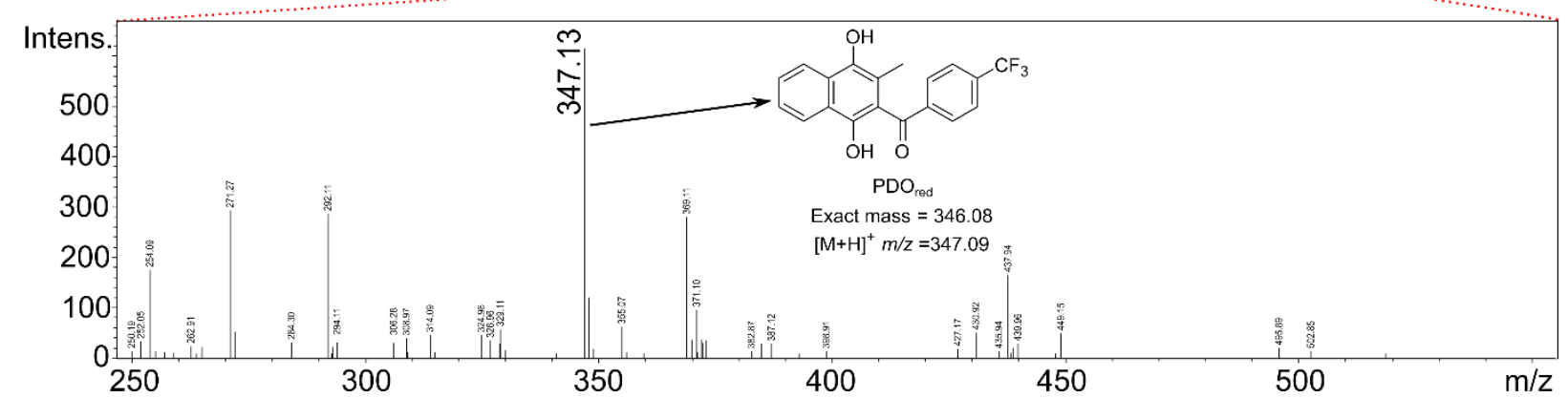

Figure 5. Redox cycling of PD by PfFNR produces PDOred. The reaction mixture consisting of $100 \mu \mathrm{M}$ of PD, $2 \mu \mathrm{M}$ PfFNR was incubated with $200 \mu \mathrm{M}$ NADPH and complemented every $15 \mathrm{~min}$ by another $200 \mu \mathrm{M}$ NADPH. After $30 \mathrm{~min}$ and $2 \mathrm{~h}$ the reaction was analyzed by HPLCMS. (A) Upper panels - $280 \mathrm{UV}$ chromatograms overlaid with extracted ion chromatograms (EIC) of reaction mixtures after 30 min or $2 \mathrm{~h}$, with or without addition of cyt $c$, evidenced the formation of PDOred. (B) Bottom panel - MS spectrum of the chromatography peak corresponding to the mass of $\mathrm{PDO}_{\text {red }}$ at $\mathrm{RT}=42 \mathrm{~min}$, after $2 \mathrm{~h}$ reaction in the presence of cyt $c$. 
A)
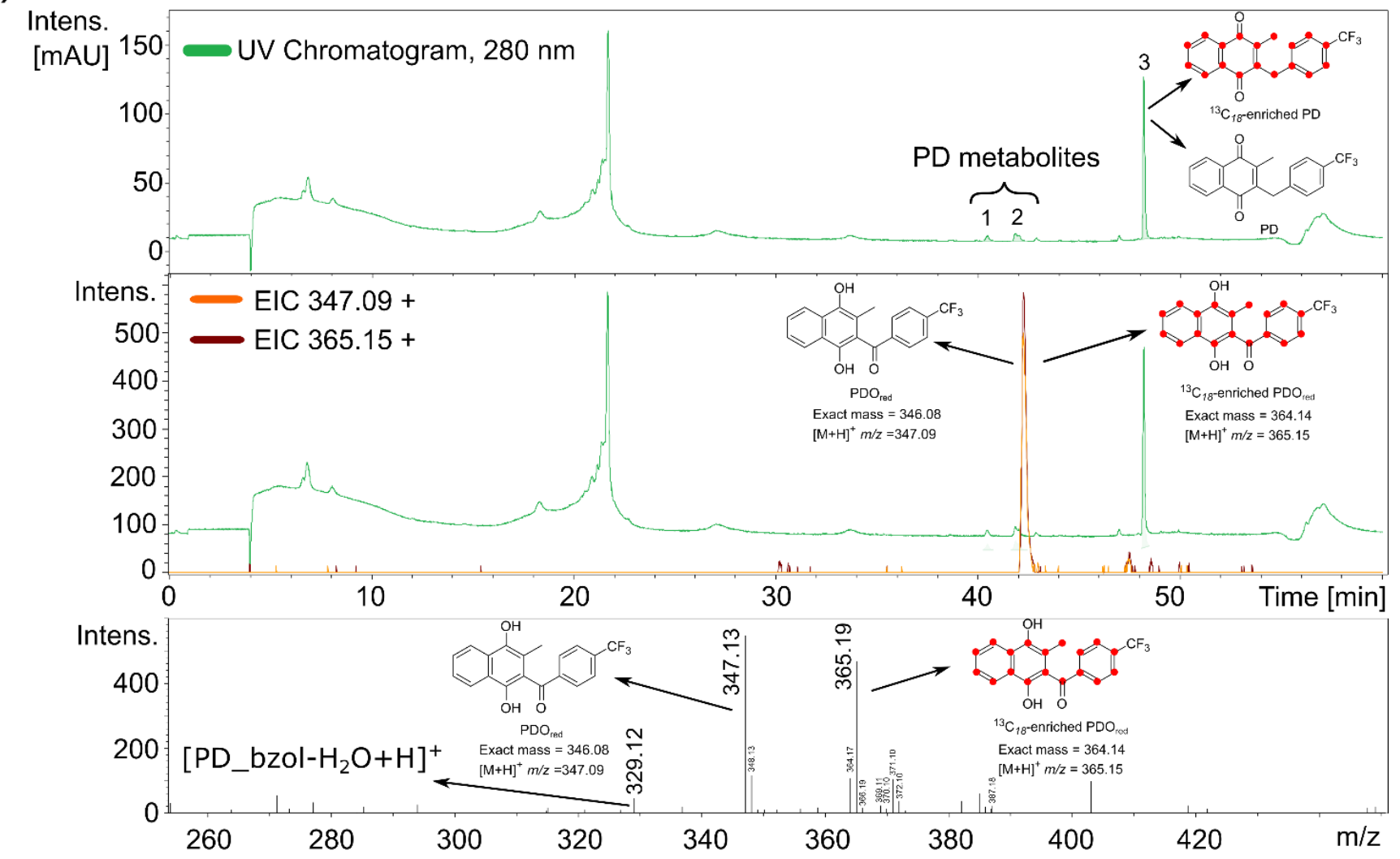

B)
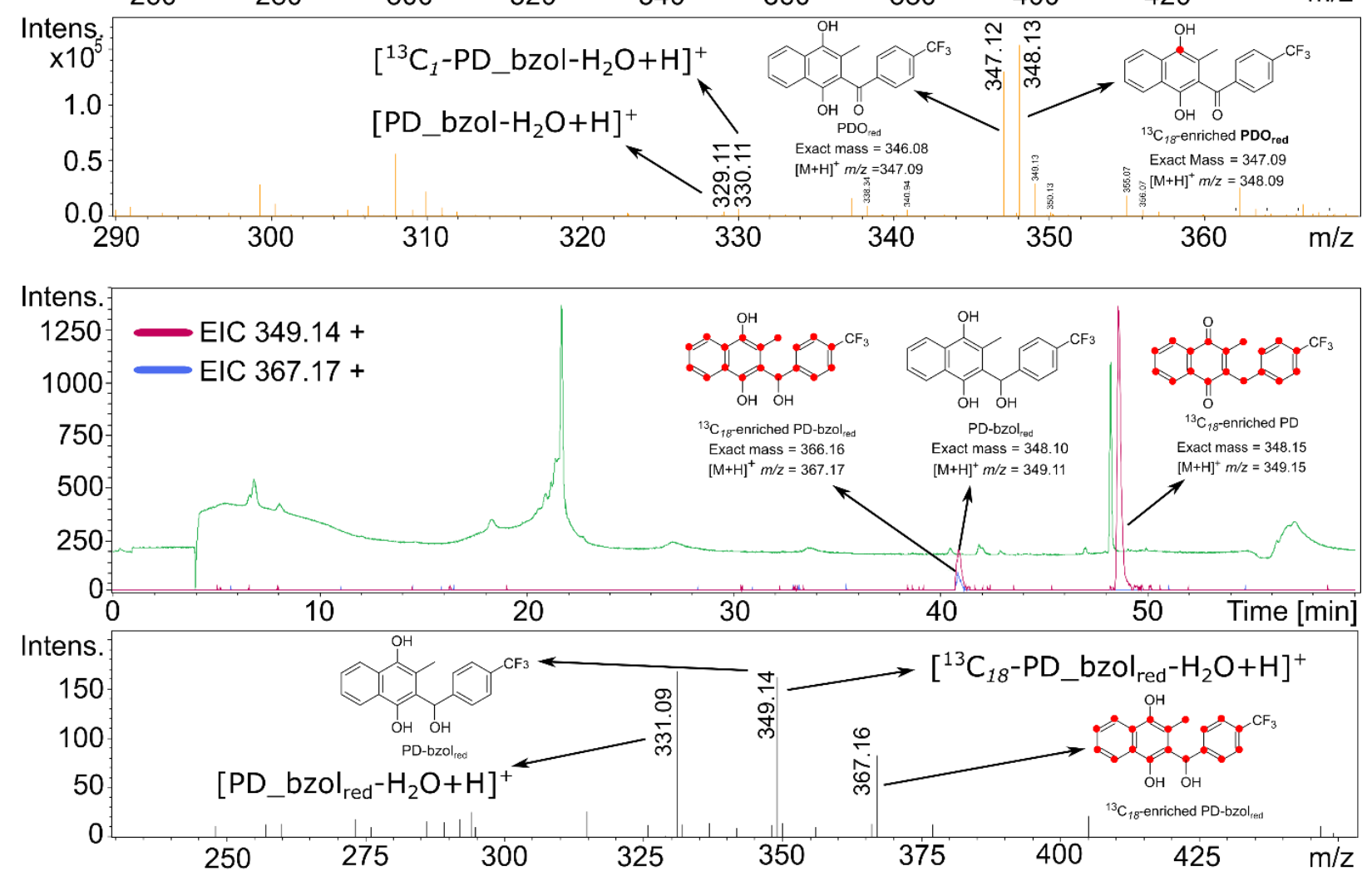

C)

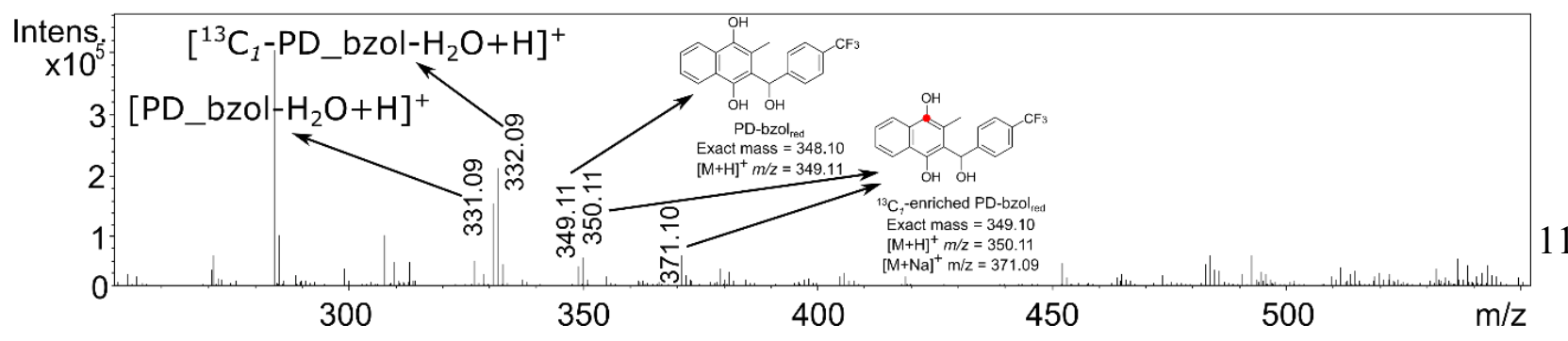


Figure 6. Redox cycling of PD catalyzed by PfFNR produces reduced PD metabolites, oxidized at the benzylic position. A) Upper panel - 280 UV chromatogram of the reaction mixture: $50 \mu \mathrm{M}$ of PD and $50 \mu \mathrm{M}$ of ${ }^{13} \mathrm{C}_{18}$-enriched PD (1/1) were mixed and incubated with $2 \mu \mathrm{M}$ PfFNR

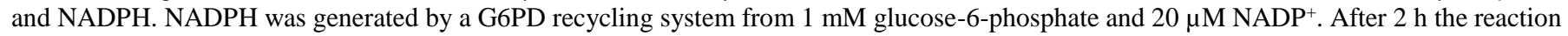
mixture was analyzed by HPLC-MS. Traces 1 and 2 - PD metabolite traces, trace 3 - PD. Middle panel - extracted ion chromatograms (EIC) corresponding to the masses of $\mathrm{PDO}_{\text {red }}$ and ${ }^{13} \mathrm{C}_{18}$-enriched $\mathrm{PDO}_{\text {red }}(\mathrm{RT}=42 \mathrm{~min})$. Lower panels $-\mathrm{MS}$ spectra corresponding to the chromatography peak at $\mathrm{RT}=41.9 \mathrm{~min}$ from the redox cycling reaction with $\mathrm{PD} /{ }^{13} \mathrm{C}_{18}-\mathrm{PD}$ or $\mathrm{PD} /{ }^{13} \mathrm{C}_{1}-\mathrm{PD}$. $\mathrm{B}$ ) Extracted ion chromatogram of the reaction mixtures in A) for the masses corresponding to the PD-bzol ${ }_{\text {red }},{ }^{13} \mathrm{C}_{18}$-enriched PD-bzol $\mathrm{l}_{\text {red }}$ species and ${ }^{13} \mathrm{C}_{18}$-enriched $\mathrm{PD}(\mathrm{RT}=40.5$ $\mathrm{min}$ ). Lower panel $-\mathrm{MS}$ spectrum of the chromatography peak at RT $=40.5 \mathrm{~min}$. C) MS spectrum of the chromatography peak at RT $=40.5$ min from a redox cycling reaction mixture as in $\mathrm{A}$ and $\mathrm{B}$ ) with enriched ${ }^{13} \mathrm{C}_{1}$-PD instead of ${ }^{13} \mathrm{C}_{18}$-PD.

These two PD metabolites are essential in the antimalarial action of the parent $\mathrm{PD}$, in particular because of their high redox cycling potential and likely generation in parasite and specifically apicoplast where PfFNR is located. The mechanism and the intrinsic level of redox cycling of quinones by various flavoenzymes, including $P f F N R,{ }^{13}$ has been investigated in Čenas's laboratory and by other groups for many years. For instance, the intrinsic reactivity of PfFNR for redox cycling of menadione is by far much more important for PfFNR than for PfGR or PfNDH2. ${ }^{12}$ The redox cycling of PD is thought to amplify the rate of formation of the semiquinone $\mathrm{NQ}^{-}$, the key intermediate to activate oxygen allowing benzylic oxidation of PD to occur, hence generating both PD metabolites, PD-bzol and PDO, in effective amount. For many years investigations on PD mode of action were performed by using the model based on both recombinant human and $P$. falciparum GRs and hemoglobin to mimick the redox cycling of PDO occurring in pRBCs. Since several studies have shown that rings - a parasitic stage where both partners (GR, metHb) of the redox-cycling might not be the major proteins - are more sensitive to PD than trophozoites $^{22}$. Also, the studies on the mode of action of PD in yeasts revealed that more relevant flavoenzymes from the mitochondrial electron transport could be more plausible protein targets involved in PD's MoA and explain the redoxcycling generating PDO from $\mathrm{PD}^{32,33}$ In the present study PfFNR is shown to generate both PD-bzol and PDO from PD during redox-cycling. All these studies are aimed at demonstrating a chemical reactivity of PD/PDO, more than identifying the exact targets of PD in each parasitic stage. This last objective, which is challenging, will hopefully be reached through our PD-ABPP strategy ${ }^{31}$ in the future.

\section{Plasmodione leads to an oxidizing effect on the apicoplast}

To investigate whether PD leads to a specific oxidizing effect on the apicoplast, we used the genetically encoded ratiometric redox-biosensor hGrx1-roGFP2 (human glutaredoxin 1 fused to oxidation-reduction sensitive green fluorescent protein) targeted to the apicoplast of $P$. falciparum. For this purpose, 3D7 P. falciparum parasites were episomally transfected with pARL1a ${ }^{(+)}$-[ACP-roGFP2-hGrx1] (referred to herein as 3D7 $7^{[\mathrm{Api}-}$ roGFP2-hGrxl] $).{ }^{41}$ Confocal life-cell imaging was performed after PD treatment using different concentration and incubation times. After short (5 min) and mid-term (4 h) incubation, low micromolar concentrations of PD led to a significant oxidizing effect in the apicoplast (Figures 7A and 7B). The degree of oxidation $(\mathrm{OxD})$ increased after short-term incubation with rising concentrations $(5 \mu \mathrm{M} P D, O x D=34.8 \% \pm 8.7 \% ; 10 \mu \mathrm{M}$ $\mathrm{PD}, \mathrm{OxD}=51.5 \% \pm 9.6 \% ; 25 \mu \mathrm{M} \mathrm{PD}, \mathrm{OxD}=69.3 \% \pm 11.4 \%$, given are mean values with SEM). Increase in OxD was even more pronounced after mid-term incubation with $39.1 \% \pm 4.9 \%$ for $1 \mu \mathrm{M}$ PD, $73.7 \% \pm 5.0 \%$ for $5 \mu \mathrm{M} \mathrm{PD}$, and $87.8 \% \pm 5.8 \%$ $\mathrm{OxD}$ after incubation with $10 \mu \mathrm{M}$ PD. Long-term $(24 \mathrm{~h})$ incubations with $50 \mathrm{nM}$ or $100 \mathrm{nM}$ PD, respectively, showed no significant effects (Figure 7C). OxD increased just slightly by $6.3 \% \pm 8.2 \%$ and $9.9 \% \pm 11.2 \%$, respectively. However, long-term treatment with $1 \mu \mathrm{M}$ and $5 \mu \mathrm{M}$ PD lead to overoxidation of the parasites (data not shown). This indicates that after $24 \mathrm{~h}$, either the parasites have overcome the treatment (with lower PD concentrations, meaning much lower generated PDO amounts) or the redox balance has decompensated.

Noteworthy is to mention that PD effect was also analyzed after incubation of $5 \mathrm{~min}, 4 \mathrm{~h}$, or $24 \mathrm{~h}$ on the glutathione redox potential in the cytosol of intact living $\mathrm{pRBCs}^{28}$ using the developed genetically encoded real-time fluorescent biosensor (hGrx1-roGFP2). ${ }^{53}$ However, in comparison, ratio changes were observed to influence the cytosolic redox potential only after $4 \mathrm{~h}$ incubation with $0.5 \mu \mathrm{M}\left(10 \mathrm{x} \mathrm{IC}_{50}\right)$ to $5 \mu \mathrm{M}(100 \mathrm{x}$ $\left.\mathrm{IC}_{50}\right) \mathrm{PD}$, and were not significant after $5 \mathrm{~min}$ incubation with up to $100 \mu \mathrm{M}$ PD $\left(2,000 \times \mathrm{IC}_{50}\right)$. The data obtained here demonstrates a decisively faster effect of PD on oxidizing redox potential in apicoplast than in cytosol of living cells.

Furthermore, previous observations made from the analysis of the morphology of synchronized parasite cultures during $46 \mathrm{~h}$ of incubation with PD have evidenced a short delay in the growth of PD-treated parasites, suggesting that the parasitic cycle was slightly retarded. ${ }^{34}$ PfFNR is localized in the apicoplast. As compounds that kill $P$. falciparum by targeting the apicoplast usually exhibit a delayed death phenotype, ${ }^{18}$ we visualized a specific oxidizing effect on the apicoplast, shortly after PD internalization, by using the genetically encoded ratiometric redox-biosensor hGrx1-roGFP2 targeted to the apicoplast of $P$. falciparum. Therefore, we can conclude that PfFNR-catalyzed redox cycling of PD through the production of PD-bzol and PDO may interfere with the electron transfer system of apicoplast, which participates in the biosynthesis of isoprenoids crucial for parasite survival. However, PfFNR might not be the sole flavoenzyme responsible for PD bioactivation and the rapid killing of parasite. Other mitochondrial target, like $\mathrm{NDH}$ and $\mathrm{SDH},{ }^{32,33}$ might redox cycle PD metabolites once generated from PD in living cells. More studies will be necessary in the future to demonstrate that the observed slight parasitic cycle retardation is consistent with an apicoplast target like $P f \mathrm{FNR}$, or that the potent antiplasmodial potency of $\mathrm{PD}$ might be associated with its redox cycling activity on $P f F N R$ and other mitochondrial flavoenzyme targets like PfSDH. Both $P f \mathrm{FNR}$ and $P f \mathrm{Fd}$ recently turned out to be both essential for parasite survival. ${ }^{17}$ As PfFNR is highly specific for NADPH, it is prone to reduce a large variety of nonphysiological one-electron-acceptors in competition with PfFd as $P f$ FNR substrates. 


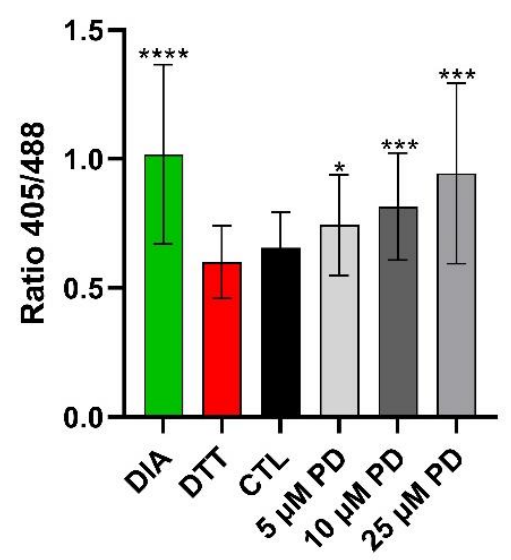

\section{B $\quad 4 \mathrm{~h}$ Incubation}
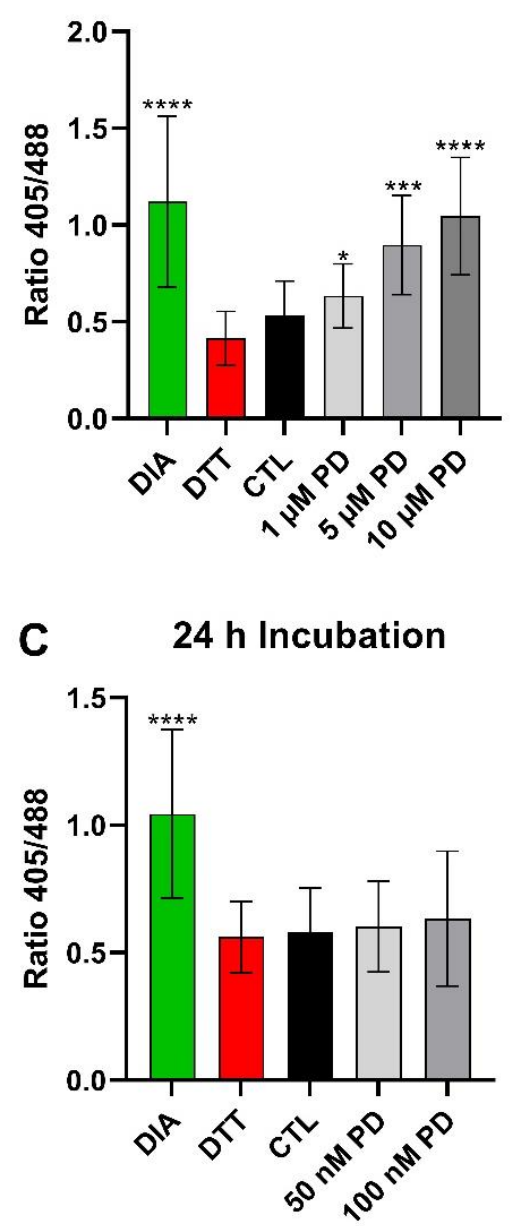

Noteworthy is to mention here the structural similarity between atovaquone and PD, both being 1,4-naphthoquinones. However, we previously showed that i) both compounds do not have redox potential values in the same range, in accordance with the fact that atovaquone is not oxidant and prone to be reduced by the model $\mathrm{GRs}^{54}$; ii) PD and its metabolites are not or are weak inhibitors of yeast complex III of the mitochondrial electron transport chain ${ }^{32}$, in contrast to atovaquone, which inhibits both yeast and $P$. falciparum bc1 complex of the mitochondrial electron transfer chain. In the case of the observed weak inhibition, e.g. by the 6-hydroxy-PD, the metabolite does not share the atovaquone binding site in the bc1 complex. ${ }^{32}$ Also, transgenic $P$. falciparum parasites rendered resistant to atovaquone by expressing the yeast dihydroorotate dehydrogenase remained sensitive towards PD. ${ }^{34}$

\section{CONCLUSION}

The $P f \mathrm{FNR} / P f \mathrm{Fd}$ couple has been proposed to be a promising target for novel antimalarial drugs, whose mechanism of action could be based on the inhibition of the enzyme, the destabilization of protein-protein interaction, or even the diversion of the electron flow away from the ironsulfur protein. ${ }^{15}$ The latter strategy is particularly attractive, due to the mentioned low efficiency of PfFd in accepting electrons from the partner. Artificial electron-acceptor substrates of PfFNR have been identified in different class of compounds, including chemicals that undergoes redox cycling in the presence of $\mathrm{O}_{2},{ }^{13}$ and here in this manuscript with the antimalarial early-lead PD. This observation is particularly relevant, since an attempt to sabotage the electron flow from $P f \mathrm{FNR}$ to $P f F d$ could indeed result, in addition to the diversion of electrons from their physiological route, to the disruption of the redox balance in the apicoplast through the rise of oxidative stress. In this work, the resulting ROS production in the apicoplast was indeed observed in transgenic parasites overexpressing the genetically encoded ratiometric redoxbiosensor hGrx1-roGFP2 targeted to the apicoplast. Thus, more attention will be given in the future to the studies investigating the impact of PD effect on specific pathways expressed in the apicoplast from malaria parasites.

Figure 7. Effect of plasmodione incubation on the glutathione-dependent redox milieu of the apicoplast after short-term (A), mid-term (B), or long-term (C) incubation. DIA, DTT and CTL stand for diamide, dithiothreitol and control, respectively. (A) Shown are the

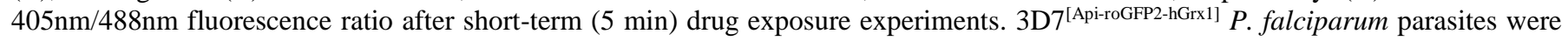
treated with $5 \mu \mathrm{M}, 10 \mu \mathrm{M}$, or $25 \mu \mathrm{M}$ PD for $5 \mathrm{~min}$. (B) Shown are the $405 \mathrm{~nm} / 488 \mathrm{~nm}$ fluorescence ratio after mid-term (4 h) drug exposure experiments. 3D $7^{[\mathrm{Api} \text {-roGFP2-hGrxl] }} P$. falciparum parasites were treated with $1 \mu \mathrm{M}, 5 \mu \mathrm{M}$, or $10 \mu \mathrm{M}$ PD for 4 h. (C) Shown are

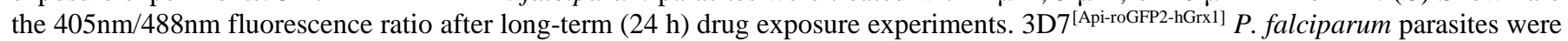
treated with $50 \mathrm{nM}$ or $100 \mathrm{nM}$ PD for $24 \mathrm{~h}$. Asterisks indicate significant differences, $* \mathrm{p}<0.05, * * \mathrm{p}<0.01, * * * \mathrm{p}<0.001, * * * * \mathrm{p}<0.0001$. Significance was calculated using GraphPadPrim8. Effects were tested in three independent experiments via CLSM, 10 parasites each were evaluated. 


\section{METHODS}

Chemicals. PD and PD-bzol synthesis was previously described in Ref. ${ }^{21,30}$, respectively. PDO and 3benzoylmenadione analogues $\mathbf{1 - 8}$ were synthesized by a recently described Friedel-Crafts reaction variant. ${ }^{29}$ The synthetic route (Scheme S1), the protocols, the chemical analysis, and NMR spectra of 3-benz(o)ylmenadione 19 and 20 are described in the supporting information. In Table $2, \log D$ values of 3-benzoylmenadione analogues 1-8 and model NQ 918 were calculated with $\log D$ predictor, (https://chemaxon.com).

Enzymes. Recombinant $P$. falciparum ferredoxin:NADP ${ }^{+}$ oxidoreductase (PfFNR) was prepared as previously described, ${ }^{14}$ and its concentration was determined spectrophotometrically according to $\varepsilon_{454}=10.0 \mathrm{mM}^{-1} \mathrm{~cm}^{-1}$. Recombinant human glutathione reductase was purified according to reported protocol ${ }^{55}$ and had a specific activity of $100.4 \mathrm{U} / \mathrm{mg}$. Cytochrome $c$ from bovine heart, bovine superoxide dismutase, glucose-6-phosphate dehydrogenase from Leuconostoc mesenteroides, NADPH, and other compounds were obtained from Sigma-Aldrich (St. Louis, MO, USA), and used as received unless specified. All kinetic experiments were carried out spectrophotometrically using a PerkinElmer Lambda 25 UV-VIS apparatus (PerkinElmer, Waltham, MA, USA) in 0.1 M phosphate-KOH buffer, $\mathrm{pH} 7.0$, containing $1.0 \mathrm{mM}$ EDTA, at $25{ }^{\circ} \mathrm{C}$. The steady-state parameters of the reactions, the catalytic constants $\left(k_{\text {cat(app) }}\right)$ and the bimolecular rate constants (or catalytic efficiency constants, $k_{\text {cat }} / K_{\mathrm{m}}$ ) for the oxidants at the fixed concentration of $100 \mu \mathrm{M}$ $\mathrm{NADPH}$, were obtained by fitting the kinetic data to a hyperbolic equation using SigmaPlot 2000, version 11.0 (SPSS Inc., Chicago, IL, USA), which correspond to the reciprocal intercepts and slopes of Lineweaver-Burk plots, $[\mathrm{E}]_{\mathrm{T}} / v_{0} v s$. $1 /$ [oxidant]), respectively, where $v_{0}$ is the initial reaction rate, and $[\mathrm{E}]_{\mathrm{T}}$ is the total enzyme concentration. $k_{\mathrm{cat}}$ represents the number of molecules of NADPH oxidized by a single active center of the enzyme per second, uuder substrate saturating condition. The rates of PfFNR-catalyzed NADPH oxidation in the presence of quinones were determined using the value $\varepsilon_{340}$ $=6.2 \mathrm{mM}^{-1} \mathrm{~cm}^{-1}$. These rates were corrected for the intrinsic $\mathrm{NADPH}$-oxidase activity of the enzyme, determined as $0.12 \mathrm{~s}^{-1}$. In separate experiments, in which $50 \mu \mathrm{M}$ cyt $c$ was included in the reaction mixture, its quinone-mediated reduction was measured using the value $\varepsilon_{550}=20 \mathrm{mM}^{-1} \mathrm{~cm}^{-1}$. The rates of oxygen consumption during the reactions were monitored using a Clark electrode (Rank Brothers Ltd., Bottisham, UK), assuming that initial oxygen concentration is $250 \mu \mathrm{M}$. The bimolecular rate constants of ascorbate oxidation by quinones $(k)$, expressed as $k=v_{0} /$ [quinone][ascorbate] (Ref. ${ }^{48}$, and references therein) were calculated from the initial rates of $\mathrm{O}_{2}$ consumption in the presence of $1.0 \mathrm{mM}$ ascorbate and various concentrations of quinones. The statistical analysis was performed using Statistica, ver. 4.3 (Statsoft, Toronto, CA).

Electrochemistry. In DMSO: The redox potentials of the PD (1.59 mM), PD-bzol (1.40 mM) and PDO (1.39 mM) were also evaluated by using cyclic (CV) and square wave voltammetries $(\mathrm{SWV})$ in $\mathrm{DMSO}^{56-58}\left(E=+0.524 \mathrm{~V} / \mathrm{Ag} / \mathrm{AgC}^{57}\right)$. The experiments were carried out at room temperature in solutions containing 0.1 of $\mathrm{M} \quad$ tetra- $n$-butylammonium hexafluorophosphate ${ }^{59}$ with a Voltalab 50 potentiostat/ galvanostat (Radiometer Analytical MDE15 polarographic stand, PST050 analytical voltammetry and CTV101 speed control unit) controlled by the Voltamaster 4 electrochemical software. A three-electrode cell $(10 \mathrm{~mL})$ composed of a glassy carbon disk (GC, $\left.s=0.07 \mathrm{~cm}^{2}\right)$ set into a Teflon rotating tube as a working electrode, a $\mathrm{Pt}$ wire as a counter electrode, and $\mathrm{KCl}(3 \mathrm{M}) / \mathrm{Ag} / \mathrm{AgCl}$ reference electrode $(+210 \mathrm{mV}$ vs $\mathrm{NHE})$ was used in this study. ${ }^{60}$ Prior any measurement, the surface of the GC electrode was freshly polished with $0.3 \mu \mathrm{m}$ aluminium oxide suspension (Escil) on a silicon carbide abrasive sheet of grit 800/2400 and then washed with water and dried with paper towel. The PD, PD-bzol or PDO solutions were vigorously stirred and purged with $\mathrm{O}_{2}$-free (Sigma Oxiclear cartridge) argon for 15 minutes before the voltammetry experiment was initiated. The cell was then maintained under argon during the measurement. For the $\mathrm{CV}$ measurements, the voltage sweep rate was varied from 50 to $300 \mathrm{mV} \mathrm{s}^{-1}$ and several cyclic voltammograms were recorded from $+0.5 \mathrm{~V}$ to $-2.2 \mathrm{~V}$. Peak potentials were measured at a scan rate of $200 \mathrm{mV} \mathrm{s}^{-1}$ unless otherwise indicated. Redox potentials were determined from oxidation and reduction potentials. The corresponding squarewave voltammetric parameters ${ }^{61}$ were used: pulse height $\left(\Delta E_{\mathrm{p}}\right)$, $50 \mathrm{mV}$; pulse width $\left(t_{\text {step }}\right), 50 \mathrm{~ms}$; step potential $\left(\mathrm{E}_{\mathrm{step}}\right), 5 \mathrm{mV}$, step amplitude, $1 \mathrm{mV}$; scan rate, $20 \mathrm{mV} \mathrm{s}^{-1}$; start, $+0.1 \mathrm{~V}$, end, $2.0 \mathrm{~V}$. In aqueous media: cyclic voltammograms were also recorded in aqueous solutions using a Parstat 2273 (PAR)

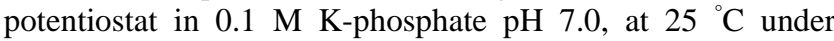
anaerobic conditions, obtained by purging the solutions with $\mathrm{Ar}$ for $20 \mathrm{~min}$. Glassy carbon (GC) working electrode (PAR, diameter $2.5 \mathrm{~mm}), \mathrm{Ag} / \mathrm{AgCl} / 3.0 \mathrm{M} \mathrm{KCl}(+210 \mathrm{mV}$ vs. NHE) reference electrode, and auxiliary $\mathrm{Pt}$ wire electrode $\left(56 \mathrm{~mm}^{2}\right)$ were used in a standard three-electrode device. The GC electrode was polished with a suspension of corundum abrasive and rinsed with deionized water. Subsequently, $2.0 \mu \mathrm{L}$ of 5.0 $\mathrm{mM}$ compound solution in DMSO were applied on the surface of GC electrode and evaporated in vacuum. The midpoint potentials of PD derivatives $\left(E^{0}{ }_{7}\right)$ are equal to the half-sum of reduction and oxidation peaks in $C V_{s}, E_{\mathrm{p}}{ }^{\text {red }}$ and $E_{\mathrm{p}}{ }^{\text {ox }}$, respectively. The apparent rate constants of electrochemical reactions of adsorbed compounds $\left(k_{\mathrm{s}}\right)$ were calculated according to a reported method $^{62}$ at potential scan rates of 0.005 $-1.0 \mathrm{~V} / \mathrm{s}$.

Photo-benzylic oxidation. Irradiation experiments for photobenzylic oxidation of PD to PDO. In a tube was added $1 \mathrm{mmol}$ of PD and $2.5 \mathrm{~mL}$ of 2-propanol. The mixture was stirred and bubbled with oxygen for $30 \mathrm{~min}$. Then, under air atmosphere or a positive pressure of oxygen, the tube was placed in a ventilated shelf of a Rayonet photochemical reactor at $16^{\circ} \mathrm{C}$ and irradiated at $350 \mathrm{~nm}$ for $72 \mathrm{~h}$. The solvent was removed under reduced pressure and the reaction crude was directly analyzed by NMR spectroscopy. Ratio between PD and PDO were calculated by integrating the $-\mathrm{CH}_{3}(\mathrm{Me})$ proton signals of $\mathrm{PD}$ and PDO (Figure 4B).

The crude product of the assay conducted in an oxygen atmosphere assay was purified by silica gel chromatography using toluene as eluent to afford the isolated PDO with $31 \%$ yield: ${ }^{1} \mathrm{H}$ NMR $\left(400 \mathrm{MHz}, \mathrm{CDCl}_{3}\right) \delta 8.23-8.13(\mathrm{~m}, 1 \mathrm{H}), 8.10$ - $8.04(\mathrm{~m}, 1 \mathrm{H}), 7.91-7.65(\mathrm{~m}, 4 \mathrm{H}), 2.09$ (s, 3H). Analytical data are in agreement with those previously described. ${ }^{21}$ 
Plasmodione redox cycling with PfFNR. To catalyze redox cycling of PD and/or ${ }^{13} \mathrm{C}$-enriched PD by PfFNR or $h \mathrm{GR}, 50$ $\mu \mathrm{M}$ of PD were mixed with $200 \mu \mathrm{M}$ NADPH in a total volume of $200 \mu \mathrm{L}$ and final DMSO concentration of $10 \%$ in $47 \mathrm{mM}$ PBS buffer. In case the reaction was speed up by cyt $c 25 \mu \mathrm{M}$ of the hemoprotein was added. The reaction was started by addition of $2 \mu \mathrm{M}$ of $P f \mathrm{FNR}$ or $h \mathrm{GR}$ and sustained by subsequent addition of $200 \mu \mathrm{M}$ of NADPH (in $4 \mu \mathrm{L}$ ) every 15 min for $2 \mathrm{~h}$. Reactions were incubated in glass tubes and $24{ }^{\circ} \mathrm{C}$ for the time of redox cycling.

For G6PD-sustained redox cycling $20 \mu \mathrm{M} \mathrm{NADP}^{+}$and $10 \mathrm{mM}$ glucose-6-phosphate were added instead of NADPH. The reaction was started by addition of G6PD $(10 \mathrm{U} / \mathrm{ml})$ and collected after $2 \mathrm{~h} 15 \mathrm{~min}$ incubation at $24-37{ }^{\circ} \mathrm{C}$. Collected samples (from NADPH and G6PD cycling) were diluted with DMSO to a $30 \%$ solvent concentration.

LC/MS analyses were performed using an Agilent 1100 series LC coupled to a MicroTOF-Q (Bruker Daltonics, Bremen, Germany). $h$ GR cycling reaction with G6PD was analyzed with the same LC system coupled to maXis II Q-TOF mass spectrometer (Bruker). The mass spectrometer operated with a capillary voltage of $4,500 \mathrm{~V}$ in positive mode. Acquisitions were performed on the mass range $m / z$ 200-1850. Calibration was performed using the singly charged ions produced by a solution of Tune mix (G1969-85000, Agilent, U.S.A.). Compounds were separated on a XBridge Peptide BEH C18

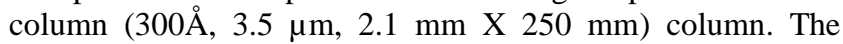
gradient was generated at a flow rate of $250 \mu \mathrm{L} / \mathrm{min}$, at $60{ }^{\circ} \mathrm{C}$ by mixing two mobile phases. Phase A consisted of $0.1 \%$ trifluoroacetic acid (TFA) in water and phase B of $0.08 \%$ TFA in ACN. Phase B was increased from 5 to $85 \%$ in 45 min. Data analysis was performed by using Compass DataAnalysis 4.3 (Bruker Daltonics).

P. falciparum cell culture. $3 \mathrm{D}^{[\mathrm{Api} \text {-roGFP2-hGrx1] }} P$. falciparum parasites were cultured with slight modifications according to the reported protocol. ${ }^{63}$ Parasites were cultured in RPMI medium (RPMI 1640 medium supplemented with $2.1 \mathrm{mM} \mathrm{L-}$ glutamine, $25 \mathrm{mM}$ Hepes, 0.5\% Albumax, $0.2 \mathrm{mM}$ hypoxanthine, $9 \mathrm{mM}$ glucose, and $22 \mu \mathrm{g} / \mathrm{ml}$ gentamycin) at $3.3 \%$ hematocrit, using $\mathrm{A}^{+}$red blood cells (RBCs). $37{ }^{\circ} \mathrm{C}$ and a gaseous mixture consisting of $3 \% \mathrm{O}_{2}, 3 \% \mathrm{CO}_{2}$, and $94 \% \mathrm{~N}_{2}$ were used for culture conditions. Parasites were synchronized using 5\% Sorbitol according to the reported procedure. ${ }^{64}$

Confocal life cell imaging. Short-term PD incubations (5 min) were performed on $P$. falciparum trophozoite-stage treated with $5 \mu \mathrm{M}, 10 \mu \mathrm{M}$, or $25 \mu \mathrm{M}$ PD. Mid-term (4 h) incubations were performed on young trophozoite-stage parasites with $1 \mu \mathrm{M}, 5$ $\mu \mathrm{M}$, or $10 \mu \mathrm{M}$ PD. For long-term $(24 \mathrm{~h})$ incubations, young ring-stage parasites were treated with $50 \mathrm{nM}, 100 \mathrm{nM}, 1 \mu \mathrm{M}$ or $5 \mu \mathrm{M}$ PD, respectively. For controls mock-treated parasites $(0.2$ $-0.5 \%$ DMSO) were used, as well as fully oxidized $(0.2 \%$ $0.5 \%$ DMSO + $1 \mathrm{mM}$ DIA) and fully reduced parasites $(0.2 \%$ $0.5 \% \mathrm{DMSO}+10 \mathrm{mM}$ DTT). The incubation times for DMSO treatment matched the different PD incubation times; the DIA and DTT incubation time was $5 \mathrm{~min}$, respectively. After $4 \mathrm{~h}$ and $24 \mathrm{~h}$ incubations, free cysteines were blocked with $2 \mathrm{mM}$ NEM for $15 \mathrm{~min}$. Trophozoite-stage parasites were magnetically enriched. ${ }^{65}$ For short-term drug exposure experiments trophozoite-stage parasites were magnetically enriched first and then incubated with $5 \mu \mathrm{M}, 10 \mu \mathrm{M}$ or $25 \mu \mathrm{M}$ PD for $5 \mathrm{~min}$.
Measurements were performed without NEM-blocking. Parasites were diluted in a pre-warmed Ringers' solution and seeded on poly- ${ }^{-}-$lysin coated $\mu$-slides VI (Ibidi, Martinsried, Germany). Life-cell imaging was performed as described ${ }^{41}$ at a Leica confocal system TCS SP5 inverted microscope equipped with the objective (HCX PL APO 63.0 x 1.30 GLYC $37^{\circ} \mathrm{C} \mathrm{UV}$ ) and a $37^{\circ} \mathrm{C}$ temperature chamber. ${ }^{41}$ Argon laser power was set to $20 \%$, the smart Gain was set to $222.0 \mathrm{~V}$ and the smart offset was $12.3 \%$. Fully reduced (10 mM DTT) and fully oxidized (1 mM DIA) parasites were used to calibrate the microscope. Data was analyzed using Leica LAS AF software. The degree of Oxidation $(\mathrm{OxD})$ was calculated as follows:

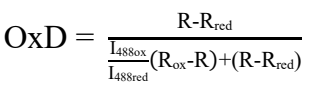

where $\mathrm{R}$ represents the ratio of the fluorescence intensity measured at $405 \mathrm{~nm}$ and $488 \mathrm{~nm}\left(\mathrm{R}=\frac{405 \mathrm{~nm}}{488 \mathrm{~nm}}\right) ; R_{\text {red }}$ and $R_{\mathrm{ox}}$ describes the ratio of the fluorescence intensities of fully reduced or fully oxidized parasites; $\mathrm{I}_{4880 x}$ is the fluorescence intensity at $488 \mathrm{~nm}$ for fully oxidized parasites; $\mathrm{I}_{488 \mathrm{red}}$ is the fluorescence intensity at $488 \mathrm{~nm}$ for fully reduced parasites. ${ }^{66}$ Graphs were plotted using GraphPadPrism8.

\section{ASSOCIATED CONTENT}

\section{Supporting Information}

Procedures and additional data: The methods for the synthesis and physico-chemical analyses used to study the investigated compounds, the NMR data of new compounds 19 and $\mathbf{2 0}$, the LC-MS data of PD metabolites analysed are available in the Supporting Information. This material is available free of charge on the ACS Publications website at doi:

\section{AUTHOR INFORMATION}

Corresponding Author

*E-mail: elisabeth.davioud@ unistra.fr (E.D.C.).

\section{Author Contributions}

\# B.A. C., M. D., K.C. H. and M. L. ranked by alphabetical order contributed equally as first co-authors to this article. M. D. and E.J. M. performed the synthesis of the derivatives 19 and 20. M. L. and M. D. measured the PfFNR kinetics in the presence of 3-benz(o)ylmenadiones. L. F. synthetized the ${ }^{13} \mathrm{C}_{18 / 1^{-}}$ enriched PD. B.A.C. carried out all metabolic studies with PD and ${ }^{13} \mathrm{C}_{18 / 1}$-enriched PD in PfFNR assays and analyzed PD metabolites by LC-MS. N. C. and E. D. C. supervised the project about PfFNR kinetics. K. C. H. and K. B. designed the hGrx1-roGFP experiment in the parasite assays in cellulo. $\mathrm{M}$. E., N. C. and E. D.-C. analyzed the data and wrote the manuscript. All authors edited the manuscript.

\section{Notes}

The authors declare no competing financial interest. 


\section{ACKNOWLEDGMENTS}

The article is dedicated to Professor Dr. Jonathan Vennerstrom's for his 65th birthday. This work was partly supported by the Laboratoire d'Excellence ParaFrap (grant LabEx ParaFrap ANR-11-LABX-0024 (E. D.-C.), the joint PHC Gilibert project between France and Lithuania (N. C . and E. D.-C.; grant $\mathrm{N}^{\circ} 42124 \mathrm{UH}$ ), and the International Center for Frontier Research in Chemistry in Strasbourg for the salary of B.A.C for 1 month to complete this study (E. D.-C. and M. E., ic-FRC-Innovation 2018 project entitled FluoPlasmo). E. D.-C. and B.A. C. are indebted to LSMBO, IPHC, for opening the mass spectrometry platform for LC-MS analysis of benzylic oxidation products and to Nathan Trometer for his valuable help in acquiring electrochemical experimental data.

\section{REFERENCES}

(1) Vennerstrom, J. L., and Eaton, J. W. (1988) Oxidants, oxidant drugs, and malaria. J. Med. Chem. 31, 1269-1277.

(2) Henderson, G. B., Ulrich, P., Fairlamb, A. H., Rosenberg, I., Pereira, M., Sela, M., Cerami, A. (1988) "Subversive" substrates for the enzyme trypanothione disulfide reductase: alternative approach to chemotherapy of Chagas disease. Proc. Natl. Acad. Sci. U S A 85, 5374-5378.

(3) Jockers-Scherübl, M. C., Schirmer, R. H., Krauth-Siegel, R. L. (1989) Trypanothione reductase from Trypanosoma cruzi. Catalytic properties of the enzyme and inhibition studies with trypanocidal compounds. Eur. J. Biochem. 180, 267-272.

(4) Čenas, N. K., Arscott, D., Williams, C. H. Jr, Blanchard, J. S. (1994) Mechanism of reduction of quinones by Trypanosoma congolense trypanothione reductase. Biochemistry 33, 2509-2515.

(5) Belorgey, D., Lanfranchi, D. A., Davioud-Charvet, E. (2013) 1,4-Naphthoquinones and others NADPH-dependent glutathione reductase-catalyzed redox cyclers as antimalarial agents. Curr. Pharm. Des. 19, 2512-2528.

(6) Blumenstiel, K., Schöneck, R., Yardley, V., Croft, S. L., Krauth-Siegel, R. L. (1999) Nitrofuran drugs as common subversive substrates of Trypanosoma cruzi lipoamide dehydrogenase and trypanothione reductase. Biochem Pharmacol. 58, 1791-1799.

(7) Salmon-Chemin, L., Lemaire, A., De Freitas, S., Deprez, B., Sergheraert, C., Davioud-Charvet, E. (2000) Parallel synthesis of a library of 1,4-naphthoquinones and automated screening of potential inhibitors of trypanothione reductase from Trypanosoma cruzi. Bioorg. Med. Chem. Lett. 10, 631635.

(8) Salmon-Chemin, L., Buisine, E., Yardley, V., Kohler, S., Debreu, M.A., Landry, V., Sergheraert, C., Croft, S. L., Krauth-Siegel, L. R., Davioud-Charvet, E. (2001) 2- and 3substituted-1,4-naphthoquinone derivatives as subversive substrates of trypanothione reductase and lipoamide dehydrogenase from Trypanosoma cruzi: synthesis and correlation between redox cycling activities and in vitro cytotoxicity. J. Med. Chem. 44, 548-565.

(9) Biot, C., Bauer, H., Schirmer, R. H. Davioud-Charvet, E. (2004) 5-Substituted tetrazoles as bioisosters of carboxylic acids. Bioisosterism and mechanistic studies on glutathione reductase inhibitors as antimalarials. J. Med. Chem. 47, 5972-5983.
(10) Buchholz, K., Schirmer, R. H., Eubel, J. K., Akoachere, M. B., Dandekar, T., Becker, K., Gromer, S. (2008) Interactions of methylene blue with human disulfide reductases and their orthologues from Plasmodium falciparum. Antimicrob Agents Chemother. 52, 183-191.

(11) Grellier, P., Marozienè, A., Nivinskas, H., Šarlauskas, J., Aliverti, A., Čènas, N. (2010) Antiplasmodial activity of quinones: roles of aziridinyl substituents and the inhibition of Plasmodium falciparum glutathione reductase. Arch Biochem Biophys. 494, 32-39.

(12) Marozienè, A., Lesanavičius, M, Davioud-Charvet, E, Aliverti, A, Grellier, P, Šarlauskas, J, Čènas, N. (2019) Antiplasmodial Activity of Nitroaromatic Compounds: Correlation with Their Reduction Potential and Inhibitory Action on Plasmodium falciparum Glutathione Reductase. Molecules 24(24), 4509.

(13) Lesanavičius, M., Aliverti, A., Šarlauskas J., Čènas N. (2020) Reactions of Plasmodium falciparum Ferredoxin:NADP+ Oxidoreductase with Redox Cycling Xenobiotics: A Mechanistic Study. Int. J. Mol. Sci. 21(9), 3234.

(14) Balconi, E., Pennati, A., Crobu, D., Pandini, V., Cerutti, R., Zanetti, G., Aliverti, A. (2009) The Ferredoxin-NADP+ Reductase/Ferredoxin Electron Transfer System of Plasmodium falciparum. FEBS J. 276, 3825-3836.

(15) Seeber, F., Aliverti, A., Zanetti, G. (2005) The plant-type ferredoxin-NADP+ reductase/ferredoxin redox system as a possible drug target against apicomplexan human parasites. Curr. Pharm. Design 11, 3159-3172.

(16) Aliverti, A., Pandini, V., Pennati, A., de Rosa, M., Zanetti, G. (2008) Structural and functional diversity of ferredoxinNADP+ reductases. Arch. Biochem. Biophys. 474, 283-291.

(17) Zhang, M., Wang, C., Otto, T. D., Oberstaller, J., Liao, X., Adapa, S. R., Udenze, K., Bronner, I. F., Casandra, D., Mayho, M., Brown, J., Li, S., Swanson, J., Rayner, J. C., Jiang, R. H. Y., Adams, J. H. (2018) Uncovering the essential genes of the human malaria parasite Plasmodium falciparum by saturation mutagenesis. Science 360(6388):eaap7847.

(18) Fichera, M. E., and Roos, D. S. (1997) A plastid organelle as a drug target in apicomplexan parasites. Nature 390, 407409.

(19) Vennerstrom, J. L., Makler, M. T., Angerhofer, C. K., Williams, J. A. (1995) Antimalarial dyes revisited: xanthenes, azines, oxazines, and thiazines. Antimicrob Agents Chemother. 39, 2671-2677.

(20) Färber, P. M., Arscott, L.D., Williams, C. H. Jr, Becker, K., Schirmer, R. H. (1998) Recombinant Plasmodium falciparum glutathione reductase is inhibited by the antimalarial dye methylene blue. FEBS Lett. 422, 311-314.

(21) Müller, T., Johann, L., Jannack, B., Brückner, M., Lanfranchi, D. A., Bauer, H., Sanchez, C., Yardley, V., Deregnaucourt, C., Schrével, J., Lanzer, M., Schirmer, R. H., Davioud-Charvet, E. (2011) Glutathione reductase-catalyzed cascade of redox reactions to bioactivate potent antimalarial 1,4-naphthoquinones - A new strategy to combat malarial parasites. J. Am. Chem. Soc. 133, 11557-11571.

(22) Ehrhardt, K., Deregnaucourt, C., Goetz, A.-A., Tzanova, T., Pradines, B., Adjalley, S. H., Blandin, S., Bagrel, D., Lanzer, M., Davioud-Charvet, E. (2016) The redox-cycler plasmodione is a fast acting antimalarial lead compound with pronounced activity against sexual and early asexual blood- 
stage parasites. Antimicrob. Agents Chemother. 60, 51465158.

(23) Bauer, H., Fritz-Wolf, K., Winzer, A., Kühner, S., Little, S, Yardley, V., Vezin, H., Palfey, B., Schirmer, H., DavioudCharvet E. (2006) A fluoro analogue of the menadione derivative 6-[2'-(3'-Methyl)-1',4'-naphthoquinolyl] hexanoic acid is a suicide substrate of glutathione reductase. Crystal structure of the alkylated human enzyme. J. Am. Chem. Soc. 128, 10784-10794.

(24) Blank, O., Davioud-Charvet, E., Elhabiri, M. (2012) Interactions of the antimalarial drug methylene blue with methemoglobin and heme targets in Plasmodium falciparum: A physico-biochemical study. Antioxid. Redox Signal. 17, 544-554.

(25) Johann, L., Lanfranchi, D. A., Davioud-Charvet, E., Elhabiri, M. (2012) A physicobiochemical study with redox-cyclers as drugs against blood feeding-parasites. Curr. Pharm. Des. 18 , 3539-3566

(26) Elhabiri, M., Sidorov, P., Cesar-Rodo, E., Marcou, G., Lanfranchi, D. A., Davioud-Charvet, E., Horvath, D., Varnek, A. (2015) Electrochemical properties of substituted 2-methyl-1,4-naphthoquinones: redox behavior predictions. Chem. Eur. J., 21, 3415-3424.

(27) Sidorov P., Desta I., Chessé M., Horvath D., Marcou G., Varnek A., Davioud-Charvet E., Elhabiri M. (2016) Redox polypharmacology is an emerging strategy to combat malarial parasites. ChemMedChem. 11, 1339-1351.

(28) Bielitza, M., Belorgey, D., Ehrhardt, K., Johann, L., Lanfranchi, D. A., Gallo, V., Schwarzer, E., Mohring, F., Jortzik, E., Williams, D. L., Becker, K., Arese, P., Elhabiri, M., Davioud-Charvet E. (2015) Antimalarial NADPHconsuming redox-cyclers as superior G6PD deficiency copycats. Antioxid. Redox Signal. 22, 1337-1351.

(29) Cotos, L., Donzel, M., Elhabiri, M., Davioud-Charvet, E. (2020) A mild and versatile Friedel-Crafts methodology for the diversity-oriented synthesis of redox-active 3benzoylmenadiones with tuneable redox potentials. Chem. Eur. J. 26, 3314-3325.

(30) Feng L., Lanfranchi D. A., Cotos L., Cesar Rodo E., Ehrhardt K., Goetz, A.-A., Zimmerman H., Fenaille F., Blandin S., Davioud-Charvet E. (2018) Synthesis of plasmodione metabolites and ${ }^{13} \mathrm{C}$-enriched plasmodione as chemical tools for drug metabolism investigation. Org. Biomol. Chem. 16, $2647-2665$.

(31) Cichocki, B., Khobragade, V., Donzel, M., Cotos, L., Blandin, S., Schaeffer-Reiss, C., Cianférani, S., Strub, J.-M., Elhabiri, M., Davioud-Charvet, E. (2021) A class of valuable (pro-)activity-based protein profiling probes: application to the redox-active antiplasmodial agent, plasmodione. JACS ${ }^{A u}$, in press. doi: https://doi.org/10.1021/jacsau.1c00025.

(32) Mounkoro, P., Michel, T., Blandin, S., Golinelli-Cohen, M. P., Davioud-Charvet, E., Meunier, B. (2019) Investigating the mode of action of the redox-active antimalarial drug plasmodione using the yeast model. Free Radic. Biol. Med. 141, 269-278.

(33) Mounkoro, P., Michel, T., Golinelli-Cohen, M.-P., Blandin, S., Davioud-Charvet, E., Meunier, B. (2021) A role for the succinate dehydrogenase in the mode of action of the redoxactive antimalarial drug, plasmodione. Free Radic Biol Med. $162,533-541$.
(34) Ehrhardt, K., Davioud-Charvet, E., Ke, H., Vaidya, A., Lanzer, M., Deponte, M. (2013) The mitochondrial electron transport chain is dispensable for the antimalarial activities of methylene blue and the lead 1,4-naphthoquinone 2-[4(trifluoromethyl)benzyl] -menadione. Antimicrob. Agents Chemother. 57, 2114-2120.

(35) Hanke, G., and Mulo, P. (2013) Plant type ferredoxins and ferredoxin-dependent metabolism. Plant Cell Environ. 36, 1071-1084.

(36) Vollmer, M., Thomsen, N., Wiek, S, Seeber, F. (2001) Apicomplexan parasites possess distinct nuclear-encoded, but apicoplast-localized, plant-type ferredoxin-NADP ${ }^{+}$ reductase and ferredoxin. J. Biol. Chem. 276, 5483-5490.

(37) Janouskovec, J., Horák, A., Oborník, M., Lukes, J., Keeling, P. J. (2010) A common red algal origin of the apicomplexan, dinoflagellate, and heterokont plastids. Proc. Natl. Acad. Sci. U.S.A. 107, 10949-10954.

(38) Rohrich, R. C., Englert, N., Troschke, K., Reichenberg, A., Hintz, M., Seeber, F., Balconi, E., Aliverti, A., Zanetti, G., Kohler, U., Pfeiffer, M., Beck, E., Jomaa, H., Wiesner, J. (2005) Reconstitution of an apicoplast-localised electron transfer pathway involved in the isoprenoid biosynthesis of Plasmodium falciparum. FEBS Lett. 579, 6433-6438.

(39) Kimata-Ariga Y, Kurisu G, Kusunoki M, Aoki S, Sato D, Kobayashi T, Kita K, Horii T, Hase T (2007) J Biochem 141, 421-8.

(40) Seeber, F., and Soldati-Favre, D. (2010) Metabolic pathways in the apicoplast of Apicomplexa. Int. Rev. Cell Mol. Biol. 281, 161-228.

(41) Mohring, F., Rahbari, M., Zechmann, B., Rahlfs, S., Przyborski, J., Meyer, A. J., Becker, K. (2017) Determination of glutathione redox potential and $\mathrm{pH}$ value in subcellular compartments of malaria parasites. Free Radical Biol. Med. 104, 104-117.

(42) O`Brien, P. J. (1991) Molecular mechanisms of quinone cytotoxicity. Chem.-Biol. Interact. 80, 1-41.

(43) Marcus, R., and Sutin, N. (1985) Electron transfers in chemistry and biology. Biochim. Biophys. Acta 811, 265-322.

(44) Nemeikaitè-Čènienè, A., Šarlauskas, J., Anusevičius, Ž. Nivinskas, H., Čènas, N. (2003) Cytotoxicity of RH1 and related aziridinylbenzoquinones: involvement of activation by $\mathrm{NAD}(\mathrm{P}) \mathrm{H}$ :quinone oxidoreductase (NQO1) and oxidative stress. Arch. Biochem. Biophys. 416, 110-118.

(45) Bailey, S. I., and Ritchie I. M. (1985) A cyclic voltammetric study of the aqueous electrochemistry of some quinones. Electrochim. Acta 30, 3-12.

(46) Patriarche, G. J., and Lingane, J. J. (1970) Anal. Chim. Acta 49, 241-246.

(47) Wardman, P. (1989) Reduction potentials of one-electron couples involving free radicals in aqueous solution. J. Phys. Chem. Ref. Data 18, 1637-1755.

(48) Marozienè, A., Nemeikaitè-Čènienè, A., Čènas, N. (2011) Studies of quinone cytotoxicity mechanisms: determination of quinone/semiquinone redox couple potential according to quinone-mediated ascorbate oxidation kinetics. Chemija 22, 162-166.

(49) Hansch, C., Leo, A., Taft, R.W. (1991) A survey of Hammett substituent constants and resonance and field parameters. Chem. Rev. 91, 165-195. 
(50) Butler, J., and Hoey, B.M. (1986) The apparent inhibition of superoxide dismutase activity by quinones. J. Free Radic. Biol. Med. 2, 77-81.

(51) Milani, M., Balconi, E., Aliverti, A., Mastrangelo, E., Seeber, F., Bolognesi, M., Zanetti, G. (2007) Ferredoxin-NADP ${ }^{+}$ reductase from Plasmodium falciparum undergoes $\mathrm{NADP}^{+}$dependent dimerization and inactivation: functional and crystallographic analysis. J. Mol. Biol. 367, 501-513.

(52) Görner, H. J. (2004) Photoreactions of 2-methyl-5-isopropyl1,4-benzoquinone. J. Photochem. Photobiol. A, 165, 215222.

(53) Kasozi D., Mohring F., Rahlfs S., Meyer A. J., Becker K. (2013) Real-time imaging of the intracellular glutathione redox potential in the malaria parasite Plasmodium falciparum. PLoS Pathog. 9(12):e1003782.

(54) Lanfranchi, D. A., Belorgey, D., Müller, T., Vezin, H., Bauer, H., Lanzer, M., Davioud-Charvet, E. (2012) Exploring the trifluoromenadione core as a template to design antimalarial redox-active agents interacting with glutathione reductase. Org. Biomol. Chem. 10, 4795-4806.

(55) Nordhoff, A., Bücheler, U. S., Werner, D., Schirmer R. H. (1993) Folding of the four domains and dimerization are impaired by the Gly446-->Glu exchange in human glutathione reductase. Implications for the design of antiparasitic drugs. Biochemistry 32, 4060-4066.

(56) Kolthoff, I. M. Treatise on analytical chemistry. Part 1, Theory and practice. V.13: Thermal methods, 2nd Revised Edition, John Wiley \& Sons, 1993, New York, United States.

(57) Ashnagar, A., Bruce, J. M., Dutton, P. L., Prince, R. C. (1984) One- and two-electron reduction of hydroxy-1,4naphthoquinones and hydroxy-9,10-anthraquinones. The role of internal hydrogen bonding and its bearing on the redox chemistry of the anthracycline antitumour quinones. Biochim. Biophys. Acta 801, 351-359.
(58) Tsierkezos, N. G. (2007) Cyclic Voltammetric Studies of Ferrocene in Nonaqueous Solvents in the Temperature Range from 248.15 to 298.15 K. J. Sol. Chem. 36, 289-302.

(59) Izutsu, K. Electrochemistry in Nonaqueous Solutions, WileyVCH, Weinheim, Germany, 2002.

(60) Sawyer, D. T., Sobkowiak, A., Roberts, J. L. Electrochemistry for Chemists, Wiley New York, 1995.

(61) Mirceski, V., Komorsky-Lovric, S., Lovric, M. Square-Wave Voltammetry: Theory and Application, Springer-Verlag Berlin Heidelberg, 2007.

(62) Laviron E. (1979) General expression of the linear potential sweep voltammogram in the case of diffusionless electrochemical systems. J. Electroanal. Chem. 101, 19-28.

(63) Trager, W., and Jensen, J. B. (1976) Human malaria parasites in continuous culture. Science 193, 673-675.

(64) Lambros, C, and Vanderberg, J. P. (1979) Synchronization of Plasmodium falciparum erythrocytic stages in culture. $J$. Parasitol. 65, 418-420.

(65) Ribaut, C, Berry, A, Chevalley, S, Reybier, K, Morlais, I, Parzy, D, Nepveu, F, Benoit-Vical, F, Valentin A. (2008) Concentration and purification by magnetic separation of the erythrocytic stages of all human Plasmodium species. Malar J. 7, 45. doi: 10.1186/1475-2875-7-45.

(66) Schuh, A. K., Rahbari, M., Heimsch, K. C., Mohring, F., Gabryszewski, S. J., Weder, S., Buchholz, K., Rahlfs, S., Fidock, D. A., Becker, K. (2018) Stable integration and comparison of hGrx1-roGFP2 and sfroGFP2 redox probes in the malaria parasite Plasmodium falciparum. ACS Infect. Dis. 4, 1601-1612. 


\section{Plasmodium falciparum ferredoxin-NADP+ reductase-catalyzed redox cycling of plasmodione generates both predicted key drug metabolites. Implication for antimalarial drug development}

Bogdan Adam Cichocki, Maxime Donzel, Kim C. Heimsch, Mindaugas Lesanavičius, Liwen Feng, Enrique Jose Montagut, Katja Becker, Alessandro Aliverti, Mourad Elhabiri, Narimantas Čènas, Elisabeth Davioud-Charvet*

Specific bioactivation of the potent antimalarial redox-active Plasmodione (PD) was demonstrated to occur by insertion of oxygen during $P$. falciparum apicoplast ferredoxin-NADP ${ }^{+}$reductase (PfFNR)-catalyzed redox-cycling via formation of a benzylic semiquinone radical. The reaction generated oxidative stress in the apicoplast of transgenic $P$. falciparum parasites expressing the glutathione redox sensor roGFP2hGrx1.

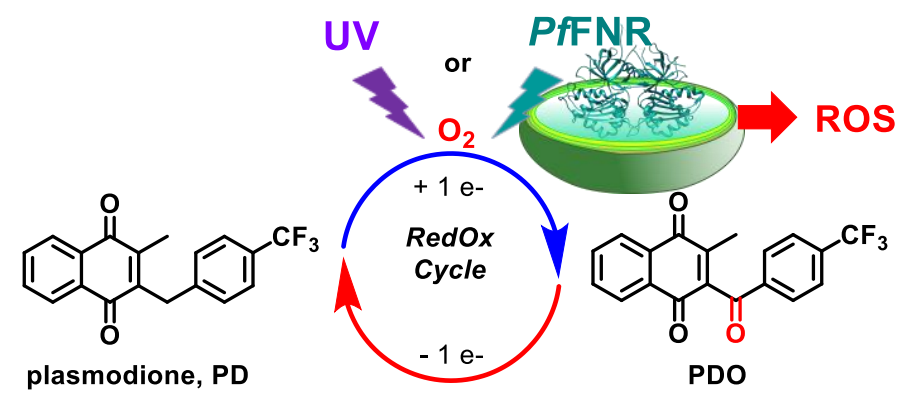

